Review Article

\title{
Carbon Nanostructure-based Sensors: A Brief Review on Recent Advances
}

\author{
Vinícius D. N. Bezzon (iD, Thaís L. A. Montanheiro $\mathbb{D}$, Beatriz R. C. de Menezes (D), \\ Renata G. Ribas $\mathbb{D}$, Victor A. N. Righetti $\mathbb{D}$, Karla F. Rodrigues $\mathbb{D}$, and Gilmar P. Thim \\ Department of Physics, Aeronautics Institute of Technology (ITA), Sao Jose dos Campos, SP 12228-970, Brazil \\ Correspondence should be addressed to Vinícius D. N. Bezzon; vinicius.bezzon@gmail.com
}

Received 12 December 2018; Revised 18 January 2019; Accepted 13 February 2019; Published 3 March 2019

Academic Editor: Stefano Bellucci

Copyright ( 2019 Vinícius D. N. Bezzon et al. This is an open access article distributed under the Creative Commons Attribution License, which permits unrestricted use, distribution, and reproduction in any medium, provided the original work is properly cited.

\begin{abstract}
A brief review reporting the recent advances on the carbon nanostructured materials-based sensors covering recently published works is presented. Several works dealing with experimental and theoretical data are reviewed and discussed. The main results for carbon nanotubes, nanodiamonds, fullerene, graphene, and hybrid carbon-nanostructured devices that show sensing properties in different fields were considered for the discussions. The goal of this paper was to highlight sensor mechanisms, and the best results reached up to now are creating bases for further applications.
\end{abstract}

\section{Introduction}

Nowadays, the necessity to develop new sensors with more specific characteristics has been increasing. Higher sensitivity and reliability, faster response, quicker recovery, low cost, reduced size, in situ analysis, and simple operation are some of the properties required for producing technological sensor devices [1]. There is an enormous number of sensors for monitoring gas, heavy metal, humidity, biomolecules, and pressure, among others. However, most of them are expensive, need pretreatment, have difficult operation and slow responses, and do not have the ideal limit of detection, sensibility, and/or selectivity.

On the perspective to improve the parameters mentioned above, nanotechnology has sponsored the most promising upgrade on materials properties providing significant advances to overcome limitations once experienced by conventional materials. Nanomaterials are produced in the nanoscale range from 1 to $100 \mathrm{~nm}$, and because of their dimension, they significantly change properties from their equivalent counterparts with structure higher than nanoscale, such as the bulk material [2].

One of the most studied and currently used material in the nanotechnology field is the carbon-based one due to its remarkable properties. Carbonaceous structures present numerous advantages compared to other usually employed materials, especially their extraordinary physical-chemical properties. Manufacture processes can be simple, yielding a proper amount of material with low densification defects. Furthermore, carbon-based materials can be considered an alternative to currently expensive electronic compounds, presenting excellent performance and being considered an environment-friendly material [3]. Therefore, carbon nanostructures have been investigated to be used as powerful sensor devices, since they present superior physical and chemical parameters yielding to high-quality sensing properties.

Several carbon-based structures discovered many decades ago are studied and applied in technological devices nowadays. Nanodiamond (ND) structure dated from the 1960s [4]. NDs are nanosized (5-100 nm) carbon structures essentially formed by $\mathrm{sp}^{3}$ hybridization [5]. Their unique optical and electronic characteristics are due to dopants present in the structure, and the excellent surface activity is assigned to structural defects and unsaturated chemical bond arising from carbon atoms [6-10]. The discovery of fullerene (FLN) occurred in 1985 through Kroto et al.'s [11] work. FLNs are a molecular allotrope of carbon and consist 
of a three-dimensional closed-cage $\left(C_{n}\right)$ made of five- and six-membered rings with 12 pentagons and a different number of hexagons, depending on the FLN size [12-16]. Another carbon-based structure is carbon nanotube (CNT) that belongs to FLN family showing a quasi-one-dimensional structure (single or multiwalled CNTs) [17]. Works on CNTs increased after the publication of Iijima in 1991 [18, 19], which studied and presented their tubular structure. The graphene (GPN) was the first discovered two-dimensional atomic crystal $[20,21]$, formed by a single atom layer of carbon atoms arranged in a honeycomb lattice structure. Figure 1 shows some of the carbon-based structures used in sensor applications.

Developing new devices sometimes requires features not found in a single material. The number of researches that have been dealing with hybrid materials has remarkably grown because of possibility to improve physical and chemical properties by composing two or more different phases. Hybrid materials, also known as composites, are systems formed by organic or inorganic components, which constitutes a particular multifunctional material class. Compounds forming hybrid materials are usually combined through a synergistic relationship [22], giving rise to unique properties to the new material because of the complementarity of unique features in each compound. Notably, studies on the new hybrid materials based on carbon structures as CNTs, GPNs, FLNs, graphene oxide (GO), and NDs have been intensively investigated for analytical applications due to their excellent properties, such as high surface area, high mechanical stability, adaptability, and functionality [23].

This report presents the latest advances concerning carbon-based sensors in several fields of applications, including mechanical, physicochemical, and biomedicine, regarding different structure arrangements. Most relevant studies will be summarily cited hereafter, and a comparison between the devices previously reported with those in this review will be presented gathering perspectives for the future of carbon-based sensor devices.

\section{Sensing Properties}

Sensor is a device that responds to a stimulus, whether chemical or physical, generating a signal that can be electronically analyzed. In order to be considered a suitable device, the sensor should have a fast response to external stimulus, be able to detect an analyte in proportion as low as possible, have low recovery time, identify the right analyte among others, and be an easy-to-operate system. Furthermore, a low-cost and environmentally friendly characteristic is desirable [24]. Thus, there is a necessity to improve systems that have been already used and find new promising alternatives that allow changing old technologies. A promising option is the use of carbonaceous nanomaterials due to their specific properties that make them suitable to be used as technological sensors. The high reactivity of different carbon structures allows functionalization, which can increase the selectivity of a desired analyte.

The characteristic of each carbon-based nanostructure allows it to be used in a specific sensor mechanism. For

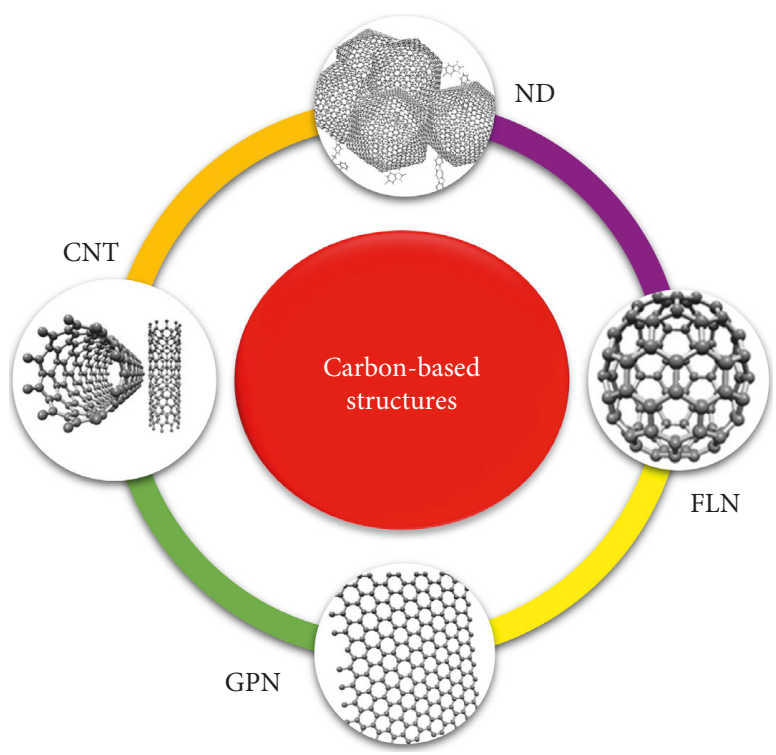

Figure 1: Carbon-based structures.

example, sensors based on NDs containing nitrogenvacancy defect centers (NV) are promising to be used in biological environments [25]. NV defects or NV centers have a delicate quantum nature that can be used to monitor external perturbations, such as magnetic or electrical fields. These centers are one of the most common defects in the diamond structure and consist of a nitrogen atom and adjacent lattice vacancy [26] and are responsible for fluorescence of NDs $[27,28]$. NDs sensing can be performed at ambient temperature and show very high sensitivity [9]. NV centers present in NDs structure enable transducing physical characteristics to an optical transition that can be recognized in single photon range, by identifying the magnetic resonance of a single or few nuclear spins. Differences in size and shape of fluorescent NDs (FNDs) also impact on the photoluminescence, chemical, and biological properties [29].

FLN has been extensively studied for producing biosensors due to improved electron-transfer kinetics, high surface-to-volume ratio, and biocompatibility [30]. Nanocomposites based on FLN, essentially $\mathrm{C}_{60}$, can be used to detect different biological molecules, including licit and illicit drugs, glucose, DNA, adenosine triphosphate (ATP), and several others. Optical and photoelectrical properties of FLNs were also explored for the development of color sensing materials [31]. In mechanical fields, FLNs present high impact strength and high resilience. The presence of fully conjugated $\pi$-electrons confined in zero dimension leads to a strong redox activity and remarkable electronic properties [16]. Also, FLN-truncated icosahedral structure is an excellent electron acceptor [32]. One of the most significant properties of FLNs is their ability to react with different molecules and functional groups. Chemical functionalization expands their potential of applications, since it increases solubility in different solvents, and combine their properties with those of other compounds [16]. Although physically stable, FLNs molecules have high electron affinity and are chemically reactive, especially with free radicals [33]. 
Due to their high surface-to-volume rate and hollow structure, CNTs have unique properties. They can adsorb a high number of molecules onto their surfaces through electronic interactions, being considered good candidates to produce chemical and biological sensors. CNTs electrical properties display excellent carrier mobilities, near-perfect quantum efficiency, and ultrathin body, allowing applications at sub- $8 \mathrm{~nm}$ scale, which is seen as a limit to development of conventional semiconductors. Advances in CNT-based electronics led to the development of CNT field-effect transistor in 1998 by Tans et al. [34], considered as a potential alternative to almost all current metal-oxidesemiconductor-field-effect transistor applications $[35,36]$.

GPN and its derivatives have been used as a raw material for sensors in different applications due to their thermal and electrical conductivity, large surface area, fast heterogeneous electron transfer rates, and high mechanical strength [3740]. Recent studies showed exceptional results for instance better sensibility, low cost, easy operation, fast response and recovery time, and good selectivity. However, defining parameters, such as the optimal number of graphene layers, or which is the best way to measure response and routes of production, is still necessary. One of the most common applications of graphene-based sensors is quantifying gases [41-43].

All structures mentioned above hold properties that can be used as sensing mechanisms depending on the desired application. Several examples of carbon-based structures applied to sensor devices are presented in the following topics. A comparison of great response sensors with others already reported is presented in the table at the end of each topic. Regarding the criteria to develop this review, studies from the last 2 years with a significant application on the sensing field were considered.

\section{Sensors Applications}

\subsection{Chemical-Properties Sensors}

3.1.1. Gas Sensor. Carbon nanostructures used as gas sensor applications have been increased because of their promising structure, which allows gas detection and quantification. The high surface-to-volume ratio and hollow structure are ideal for adsorption and desorption of gas molecules. Besides, the possibility of functionalization increases gas selectivity. Carbon nanostructures can be used in different types of sensor systems (sorption, ionization, capacitance, or resonance frequency shift) satisfying the criteria for the efficiency of gas sensors, such as high sensitivity and selectivity, fast response and recovery time, and stability [44]. Usually, the operating principle of these systems is the variation of applied voltage and current, concerning the number of gas molecules adsorbed onto the surface structure. An electrical signal is generated during the interaction between molecules and sensor.

One of the main applications of carbonaceous materials as gas sensors is for detection and quantification of polluting gases, especially hydrogen sulfide $\left(\mathrm{H}_{2} \mathrm{~S}\right)$, carbon monoxide $(\mathrm{CO})$, carbon dioxide $\left(\mathrm{CO}_{2}\right)$, nitrogen oxide $\left(\mathrm{NO}_{x}\right)$, ammonia $\left(\mathrm{NH}_{3}\right)$, and methane $\left(\mathrm{CH}_{4}\right)$. There is a special concern about controlling gas pollutants in the air because they induce side effects for the environment and human health. GPN, GO, CNTs, and, most recently, FLN are the main allotropic forms of carbon used in this type of sensor.

$\mathrm{NO}_{2}$ gas, among others, is not the only responsible for acid rain but is also harmful to the respiratory system of human beings when its concentration is above the threshold limit [45]. The recommended annual exposure limit of $\mathrm{NO}_{2}$ is $53 \mathrm{ppb}$, according to the US Environmental Protection Agency [46]. So, a highly sensitive sensor system to identify low proportions of $\mathrm{NO}_{2}$ gas in the air is necessary. Seekaew et al. [47] developed a highly sensitive room-temperature gas sensor depositing a GPN bilayer onto Ni electrodes. The authors compared the performance of bilayer GPN gas sensor at room temperature with samples of monolayer and multilayer of GPN. To control the number of layers, researchers used Chemical Vapor Deposition (CVD) technique. Bilayer sensor showed the highest sensibility of the three samples, $1409 \mathrm{ppm}^{-1}$ towards $\mathrm{NO}_{2}$ over a concentration range of $1-25 \mathrm{ppm}$, which is more than twice higher than that one with GPN monolayer. Moreover, bilayer sensor presented high selectivity to $\mathrm{NO}_{2}$ against $\mathrm{CO}, \mathrm{CO}_{2}$, $\mathrm{NH}_{3}$, ethanol $\left(\mathrm{C}_{2} \mathrm{H}_{5} \mathrm{OH}\right)$, and hydrogen gas $\left(\mathrm{H}_{2}\right)$.

Ricciardella et al. [48] investigated the influence of different methodologies to produce GPN on morphology, crystalline structure, and consequently on the performance of $\mathrm{NO}_{2}$ sensors synthesized from these materials. Among the three different synthesis routes, mechanical exfoliation (ME) presented less-defective material, with the highest value of signal variation than that one obtained through Liquid Phase Exfoliation (LPE) and CVD techniques. They demonstrated that a low defectiveness level induces a faster interaction during the exposure time towards the gas.

In another work, $\mathrm{Wu}$ et al. [49] synthesized a superhydrophobic reduced GO (rGO) for $\mathrm{NO}_{2}$ detection. The presence of functional groups such as hydroxyl, epoxide, and carboxylic in GO, not only decreases the conductance of graphene, but also makes GO-based gas sensors extremely vulnerable to humidity, considering that these groups are extremely hydrophilic. Using spark plasma sintering, authors were able to remove most of the oxygenated functional groups due to the high vacuum environment, the spark plasma generated, and the high temperature, which boosted the reduction process. Reduction of GO in rGO not only produced a superhydrophobic property, but increased surface areas with large defects that promoted gas adsorption. The increases of surface area and defects sites improve sensibility and adsorption of gas, respectively. The $\mathrm{NO}_{2}$ sensor presented high sensitivity $\left(25.5 \mathrm{ppm}^{-1}\right)$ and a remarkably low limit of detection (9.1 ppb). This performance is attributed to superhydrophobicity, high surface area $\left(850 \mathrm{~m}^{2} / \mathrm{g}\right)$, and abundance of defect sites.

There is a necessity of monitoring toxic gases besides $\mathrm{NO}_{2}$ in the environment to protect everyone from injuries provoked by air pollutants. For example, above the $100 \mathrm{ppm}$ level, $\mathrm{H}_{2} \mathrm{~S}$ can induce an immediate collapse with loss of breathing and could lead to death $[45,50,51]$. In a recent investigation [43], researches developed an $\mathrm{H}_{2} \mathrm{~S}$ gas sensor 
based on graphene decorated with Ag nanoparticles. Doped graphene sensor exhibited selectivity in the presence of $\mathrm{CH}_{4}$, $\mathrm{CO}_{2}, \mathrm{~N}_{2}, \mathrm{O}_{2}$, and a limit of detection below the recommended $100 \mathrm{ppm}$. Furthermore, this new device presented fast response $(\sim 1 s)$ and short recovery time ( $\sim 20 s)$, allowing real-time $\mathrm{H}_{2} \mathrm{~S}$ monitoring with immediate response.

Keshtkar et al. [52] synthesized a nanohybrid tin oxide $\left(\mathrm{SnO}_{2}\right)$ quantum dots- $\mathrm{C}_{60}$ FLN by a hydrothermal method to be applied as a gas sensor. Different gases were used in the study, including $700 \mathrm{ppm} \mathrm{H}_{2} \mathrm{~S}$ at low temperatures from $100^{\circ} \mathrm{C}$ to $200^{\circ} \mathrm{C}$. The results presented in this study showed high response and selectivity of the sensor system for all gases, being $\mathrm{H}_{2} \mathrm{~S}$ the gas with the highest response, obtained by the high ratio between sensor resistance in air and tested gas environment $\left(R_{\text {air }} / R_{\text {gas }}\right)$. Authors performed density functional theory (DFT) calculations to determine the most favorable gas regarding interaction energy and band gap. $\mathrm{H}_{2} \mathrm{~S}$ showed strong interaction and high effect on band-gap variation that is in good agreement with the experimental results.

$\mathrm{NH}_{3}$ is other gas to be monitored due to surface water pollution, soil eutrophication, and acidification [53]. Kodu et al. [42] elaborated GPN functionalized with vanadium pentoxide $\left(\mathrm{V}_{2} \mathrm{O}_{5}\right)$ using laser ablation technique for the production of a highly sensitive $\mathrm{NH}_{3}$ sensor. Compared to unmodified graphene, the sensor with a thin $\mathrm{V}_{2} \mathrm{O}_{5}$ layer $(\sim 6 \mathrm{~nm})$ obtained by CVD improved the sensing of ammonia at ambient temperature. Electrical conduction response to $20 \mathrm{ppm}$ of $\mathrm{NH}_{3}$ increased from 6.5 to $26.0 \%$, which indicates an improvement of sensitivity.

$\mathrm{CH}_{4}$ is a component of natural gas that can cause asphyxiation and explosions when present in a substantial concentration on nonventilated areas. Chen et al. [54] made up a sensor of $\mathrm{Li}^{+}$doped CNTs producing a $\mathrm{Li}^{+} / \mathrm{CNT}$ film. Under $\mathrm{CH}_{4}$ exposure, $\mathrm{Li}^{+} / \mathrm{CNT}$ sensor has its conductivity changed through electrochemical reaction due to the gas adsorbed molecules. $\mathrm{Li}^{+}$strengthen up binding of $\mathrm{CH}_{4}$ and induce dipole interaction between them. Thus, the change on hybridization state from $\mathrm{sp}^{2}$ to $\mathrm{sp}^{3}$, related to adding $\mathrm{CH}_{4}$ to p-bonds of CNTs, interferes to the system's resistance. This sensor showed a sensitivity of $14.5 \%$ at $500 \mathrm{ppm}$ of $\mathrm{CH}_{4}$, which makes it an excellent device to be more exploited and applied.

Although $\mathrm{H}_{2}$ is not polluting, it presents high flammability, generating concerns about its production, storage, and transportation [55]. Jaidev et al. [55] developed a sensorbased on CNTs coated with GPN (GCNTs) and decorated with $\mathrm{Pt}$ nanoparticles for $\mathrm{H}_{2}$ detection. CNT and GPN were used to promote high surface area and good electrical conductivity for the sensor. However, these carbon materials are almost insensitive under some gas exposure, such as $\mathrm{H}_{2}$. Therefore, Pt has been applied in consequence of its high catalytic activity towards $\mathrm{H}_{2}$. GCNTs were prepared using single-furnace catalytic CVD (CCVD) technique. Then, GCNTs were decorated with Pt nanoparticles in different amounts by the ethylene glycol reduction technique. GCNTs dispersed in ethanol were dropped onto the substrate. Gassensing operation was studied by measuring resistance change of the film on switching gas environment from air to
$\mathrm{H}_{2}$ in cyclic regime. Main results obtained were that the sensor showed a stable and reproducible response towards hydrogen. Authors concluded that higher $\mathrm{H}_{2}$ concentrations result in a better response. However, with the increase in temperature, sensitivity was reduced.

Algadri et al. [56] fabricated $\mathrm{H}_{2}$ gas sensor using dielectrophoresis technique to obtain a sensor with a glass substrate and Pd electrodes. Multiwalled CNTs (MWCNTs) were produced through a mix of graphite and ferrocene heated in a microwave oven and treated with nitric acid at room temperature. MWCNTs were deposited onto a glass substrate between Pd electrodes using the technique mentioned above. This device showed high sensitivity (maximum sensitivity of $239 \%$ ) when exposed to 20-1000 ppm mixture of $\mathrm{H}_{2}-\mathrm{N}_{2}$ and under a voltage of $0.05 \mathrm{~V}$. The model proposes that MWCNTs generate a passageway for the current to move faster under the voltage application, increasing the sensitivity of the gas sensor. $\mathrm{H}_{2}$ molecules' adsorption mechanism concerns to the molecule being absorbed onto the external surface of MWCNTs, tubes' interior, external groove, and interstitial channels, where the binding energy channels are higher than other ones [56, 57].

The potential of using carbonaceous materials as a gas sensor has also been explored to detect $\mathrm{C}_{2} \mathrm{H}_{5} \mathrm{OH}, \mathrm{O}_{2}$, and rare gases. Smazna et al. [58] fabricated $\mathrm{C}_{60}$ FLN-decorated zinc oxide $(\mathrm{ZnO})$ tetrapod materials for ethanol gas sensing applications. Clusters of $\mathrm{C}_{60}$ were deposited onto $\mathrm{ZnO}$ surfaces changing absorption and luminescence properties of $\mathrm{ZnO}$ tetrapods. Higher amounts of $\mathrm{C}_{60}$ resulted in steeper $\mathrm{ZnO}$ band gap absorption and a well-defined free excitation. An active charge transfer phenomenon from $\mathrm{C}_{60}$ to $\mathrm{ZnO}$ was also observed. DFT study confirmed the experimental results, suggesting interesting sensing behavior. Results showed a promising use of this new device as an ethanol gas sensor.

$\mathrm{C}_{20}$ FLN has also been investigated to be used as a gas sensor, especially for the detection of diatomic and rare gas. Zhao et al. [59] studied transport properties of $\mathrm{C}_{20}$ molecular junctions for detection of $\mathrm{NO}, \mathrm{CO}$, and $\mathrm{O}_{2}$. Authors used nonequilibrium Green's function formalism combined with DFT to calculate the most stable adsorption structural configurations, adsorption energy, and transport properties on $\mathrm{C}_{20}$ molecular junctions with these diatomic gas molecules. Results showed that $\mathrm{NO}$ and $\mathrm{O}_{2}$ could be detected selectively, while $\mathrm{C}_{20}$ is limited to sensing CO. Authors suggested that $\mathrm{C}_{20}$ FLN shows excellent potential to be used as nanosensors for gas detection [59]. Similar work was performed by Rahimi et al. [60], where pristine and Scdoped $\mathrm{C}_{20}$ FLN were investigated through DFT as a rare gas sensor. Results showed that the adsorption of rare gas molecules by $\mathrm{C}_{20}$ significantly changed its electronic nature, especially for Sc-doped $\mathrm{C}_{20}$. Authors concluded that adsorption of a rare gas on the surface of Sc-doped $\mathrm{C}_{20}$ is a promising strategy for the development of new rare gas adsorbent and sensors.

Besides the identification and quantification of previously cited gases, carbon-based sensors can also be used to determine the temperature of ionized gases. An interesting gas sensor system was developed by Song et al. [61], where 
authors proposed a novel ionized gas temperature sensor that has sensitivity to which type of gas is being detected as well as to obtain the gas temperature. The triple-electrode device has a cathode and extracting and collecting electrodes. Vertically aligned CNTs are disposed onto the cathode, and voltage is applied between the electrodes. In such systems, CNTs plays an essential role in featuring electrical breakdown, since such systems do not evolve adsorption/desorption of gas molecules. Gas temperature affects the degree of ionization and emission current that influences the collecting current. This sensor could detect temperatures from $20^{\circ} \mathrm{C}$ to $110^{\circ} \mathrm{C}$ with a sensitivity of $4.74 \mu \mathrm{A}^{\circ} \mathrm{C}^{-1}$ (air) and $22.72 \mu \mathrm{A}^{\circ} \mathrm{C}^{-1}\left(\mathrm{~N}_{2}\right)$, both at $110^{\circ} \mathrm{C}$. Another work was published [62] using the same ionization gas sensor feature, but in this case for NO detection. It exhibited the highest sensitivity of $5.5 \mathrm{nA} \cdot \mathrm{ppm}^{-1}$ at $330 \mathrm{ppm}$ of NO, with fast response and short recovery time.

Table 1 presents a comparison between the results obtained by some of the sensors discussed in this topic ("Sensor compound or device," "Sensitivity/linear range/LOD," and "Great response for" columns) with other works previously reported "Other reported systems" and "Responses from other systems" columns) not discussed above. The column "Other reported systems" is related to examples of sensor systems reported before the system in the first column.

3.1.2. Molecules and Chemical Elements. Detecting organic molecules and chemical elements yield improvements for the environment. One can create certain conditions to eliminate contamination, or even to phase out the contaminant through monitoring dangerous compounds all around. Carbon-based sensors offer great feasibility to be used in these situations, with response as good as that for gas sensing. For example, besides monitoring $\mathrm{NO}_{2}$ and other gases in the atmosphere, controlling nitrogen on water is a current concern for health care. The nitrogen cycle is fundamental for many living beings and comes from one of the nutrient sources, nitrates. However, excessive nitrate concentration in water causes a threat to aquatic environments and human health. Water eutrophication is an environment problem since it could decrease the oxygen rate, leading fishes and other animals to death $[82,83]$.

Alahi et al. [84] developed a low-cost nitrate-sensor based on GPN structure. Among the advantages of this new device compared to other methodologies, corrosion resistance is a desired property due to the application in water. Besides that, high porosity yields an increase in the sensing area. This GPN sensor has, compared to traditional approaches, real-time response, low cost, and less sample preparation time and presents an error below 5\%. Results were validated with laboratory-standard method UVspectrometry. Besides the broad application of GPN-based sensors, much more studies must be done to optimize these devices. Chen et al. [37] also developed a nitrate-sensor, which is a new device for monitoring nitrate using rGO combined with benzyltriethylammonium chloride (Betec). This sensor showed a quick response $(2-7 \mathrm{~s})$, low limit of detection $(1.1 \mu \mathrm{g} / \mathrm{L})$, and selectivity against interfering ions
$\left(\mathrm{Cl}^{-}, \mathrm{SO}_{4}{ }^{2-}, \mathrm{CO}_{3}{ }^{2-}\right)$. The challenge for the sensor application is controlling immobilization of $\mathrm{rGO}$ sheets on electrodes with homogeneous dispersion to decrease device-to-device variations.

FLN-based nanocomposites have also been used to determine the content of organic and inorganic compounds in water for monitoring water quality. Wei et al. [85] proposed a new photocatalytic sensor for organic compounds detection based on $\mathrm{Au}$ and titanium dioxide $\left(\mathrm{TiO}_{2}\right)$ nanoparticles and $\mathrm{C}_{60} \mathrm{FLN}\left(\mathrm{Au}-\mathrm{TiO}_{2}-\mathrm{C}_{60}\right)$. $\mathrm{TiO}_{2}$ is a traditional catalyst material already used in photodegradation systems. Au nanoparticles were introduced as cocatalyst and plasmonic sensor while $\mathrm{C}_{60}$ was used as an accelerator for the redox reaction. During redox reactions, the repeated shifts of the nanoplasmonic peak of $\mathrm{Au}$, as a result of electron transfer, was observed using surface plasmon spectroscopy. The frequency of plasmonic swing indicated reaction rate and was used to determine the concentration of organics in water. High precision and sensibility were observed, indicating a great potential to use the plasmonic sensor in water quality determinations.

Heidari and Masrournia [86] modified two carbon paste electrodes, one using 3-methylpyrazol-5-one and the second using MWCNT functionalized with acyl chloride $(\mathrm{COCl})$ as modifiers for determination of $\mathrm{Cr}(\mathrm{III})$ in water. Carbon paste electrodes are popularly used in electrochemical studies. The modifiers amount ranged from 10 to $20 \mathrm{wt} . \%$ in a mixture with graphite powder, paraffin oil, and zeolite. Results showed that the electrode with functionalized MWCNT had a wider measuring range, lower detection rate $\left(5 \times 10^{-8} \mathrm{M}\right)$, and broader $\mathrm{pH}$ range (3.0 to 9.0) compared to other selective electrodes.

Phenolic compounds are severe pollutants that need adequate monitoring to reduce their effect in the environment. Detections of monophenols and biphenols were investigated by Jiang et al. [87] through the development of boron-doped NDs electrochemical sensors. ND particles were dropped onto glassy carbon electrodes (GCEs) to obtain the sensors. Authors noticed that ND-GCE electrodes did not show enzyme biocompatibility, which was associated with its $\mathrm{sp}^{3}$ hybridization. The study also revealed exceptional inertness of ND against phenolic compounds and wide detection range of ND-GCE compared to nanocarbonGCE and GPN-GCE. Chen [88] also developed a modified GCE electrode to detect hydroquinone (HQ), an aromatic phenolic compound. The developed ND-GCE electrode not only intensified current response but additionally registered lower oxidation potential when confronted with unmodified GCE, displaying a high selectivity for detection of $\mathrm{HQ}$.

The accumulation of heavy metals in the ambient can occur through the food chains and cause many health issues, for instance, liver and kidney failure, even when the exposure levels are deficient [89, 90]. Liu et al. [38] fabricated a GPN sensor for detecting ions such as $\mathrm{Cd}^{2+}, \mathrm{Pb}^{2+}$, and $\mathrm{Cu}^{2+}$ by the anodic stripping voltammetry method. Highly conductive GPN films were synthesized by a vacuum press method and were used as disposable electrodes for heavy metal analysis. Results showed a linear range from 5 to $400 \mu \mathrm{g} \cdot \mathrm{L}^{-1}$ and detection limit of $0.5 \mu \mathrm{g} \cdot \mathrm{L}^{-1}$ for Cd ion, 
TABle 1: Comparison between discussed gas sensor responses and different systems found in the literature.

\begin{tabular}{|c|c|c|c|c|}
\hline $\begin{array}{l}\text { Sensor compound } \\
\text { or device }\end{array}$ & Sensitivity/linear range/LOD & $\begin{array}{l}\text { Great } \\
\text { response } \\
\text { for }\end{array}$ & Other reported systems & $\begin{array}{l}\text { Responses from other } \\
\text { systems }\end{array}$ \\
\hline Bilayer GPN [47] & $\begin{array}{c}12.87 \% \text { at } 5 \mathrm{ppm}^{\left(\mathrm{RT}^{*}\right)} \text { and } \\
1.409 \mathrm{ppm}^{-1}\end{array}$ & $\mathrm{NO}_{2}$ & $\begin{array}{c}\text { Monolayer and multilayer } \\
\left(0.696 \mathrm{ppm}^{-1} \text { and } 0.498 \mathrm{ppm}^{-1}\right) \text { [47] }\end{array}$ & $\begin{array}{c}\text { Less than } 10 \% \text { at } 5 \mathrm{ppm} \text { and } \\
0.5 \mathrm{ppm}^{-1} \\
\text { (GPN-based sensors) }\end{array}$ \\
\hline $\begin{array}{l}\text { Superhydrophobic } \\
\text { rGO [49] }\end{array}$ & $\begin{array}{l}93 \% \text { at } 1 \mathrm{ppm}\left(\text { at } 140^{\circ} \mathrm{C}\right) \text { and } \\
25.5 \mathrm{ppm}^{-1}\end{array}$ & $\mathrm{NO}_{2}$ & 3D-rGO [63] & $\mathrm{NR}^{* * *}$ \\
\hline $\mathrm{GPN}-\mathrm{V}_{2} \mathrm{O}_{5}[42]$ & $\begin{array}{c}12.0 \% \text { at } 1 \mathrm{ppm}(\mathrm{RT}) \text { and } 26.0 \% \\
\text { at } 20 \mathrm{ppm}(\mathrm{RT})\end{array}$ & $\begin{array}{l}\mathrm{NO}_{2} \\
\text { and } \mathrm{NH}_{3}\end{array}$ & $\begin{array}{l}\text { Exfoliated } \mathrm{Gr}[64] ; \mathrm{SiC} / \mathrm{Gr}+\mathrm{Au}[65] \\
\text { defective CVD Gr }[66,67] ; \mathrm{B}-\text { doped } \\
\text { CVD Gr [68] }\end{array}$ & $\begin{array}{l}4 \% \text { to } 55 \% \text { in the range from } \\
0.02 \mathrm{ppm} \text { to } 200 \mathrm{ppm}\end{array}$ \\
\hline $\mathrm{SnO}_{2} \mathrm{QDs} \mathrm{C}_{60}[52]$ & $\begin{array}{c}66.0\left(R_{\mathrm{a}} / R_{\mathrm{g}}{ }^{* *}\right) \text { at } 70 \mathrm{ppm} \\
\left(\text { at } 150^{\circ} \mathrm{C}\right)\end{array}$ & $\mathrm{H}_{2} \mathrm{~S}$ & $\begin{array}{c}\mathrm{SnO}_{2} \mathrm{QW} / \mathrm{rGO}[69] \\
\mathrm{SnO}_{2} \mathrm{NFs} / \mathrm{rGO}[70] \\
\mathrm{SnO}_{2} \text { multitube arrays [71] }\end{array}$ & $\begin{array}{c}33.0 \text { at } 50 \mathrm{ppm}(\text { at RT); } \\
33.7 \text { at } 5 \mathrm{ppm}\left(\text { at } 200^{\circ} \mathrm{C}\right) \\
1.45 \text { at } 5 \mathrm{ppm}(\text { at RT) }\end{array}$ \\
\hline $\mathrm{Li}^{+} / \mathrm{CNT}[54]$ & $14.5 \%$ at $500 \mathrm{ppm}$ & $\mathrm{CH}_{4}$ & Unmodified CNT sensor [54] & $4.8 \%$ at $500 \mathrm{ppm}$ (at RT) \\
\hline GCNTs/Pt & $42.8 \%$ at $4 \% \mathrm{H}_{2}$ in air & $\mathrm{H}_{2}$ & $\begin{array}{l}\mathrm{Pt} / \mathrm{CNTs}[72-74] ; \mathrm{Pd} / \mathrm{CNTs}[75] ; \mathrm{Pt}- \\
\mathrm{Pd} / \mathrm{CNTs}[76] ; \mathrm{Pd} / \mathrm{CNT} / \mathrm{rGO}[77]\end{array}$ & $\begin{array}{c}2 \% \text { to } 35 \% \text { in the range } \\
1 \% \text { to } 4 \% \text { of } \mathrm{H}_{2}\end{array}$ \\
\hline $\begin{array}{l}\text { CNT onto glass subs. } \\
\text { Between Pd } \\
\text { electrodes [56] }\end{array}$ & $\begin{array}{l}208 \% \text { to } 359 \% \text { in the range } \\
20 \mathrm{ppm} \text { to } 1,000 \mathrm{ppm}\left(100^{\circ} \mathrm{C}\right)\end{array}$ & $\mathrm{H}_{2}$ & Single and multiwalled CNT [78-81] & $\begin{array}{l}0.58 \% \text { to } 200 \% \text { in the range } \\
100 \mathrm{ppm} \text { to } 80,000 \mathrm{ppm}\end{array}$ \\
\hline
\end{tabular}

$1.0 \mu \mathrm{g} \cdot \mathrm{L}^{-1}$ for $\mathrm{Pd}$ ion, and $5.0 \mu \mathrm{g} \cdot \mathrm{L}^{-1}$ for $\mathrm{Cu}$ ion. The detection limit recommended by the World Health Organization is $10 \mu \mathrm{g} \cdot \mathrm{L}^{-1}$, which is in accordance with the results presented. GPN sensors fabricated by Liu and coworkers were compared to other researches. Except for $\mathrm{Cu}$ ion, results were better for GPN electrodes presented in this study.

In a different investigation, a "turn-on" fluorescence sensor for $\mathrm{Pb}^{2+}$ detection based on GPN quantum dots (QD) and gold nanoparticles was fabricated [91]. Researchers achieved an enormous broad detection range of $\mathrm{Pb}^{2+}$ from $50 \mathrm{nM}$ to $4 \mu \mathrm{M}$, with a detection limit of $16.7 \mathrm{nM}$. Nanoparticles were immobilized with amine-modified combined strand by 1-ethyl-3-(3-dimethyl-aminopropyl) carbodiimide. The combination of GPN QD and nanoparticles led to fluorescence quenching and recovery. The sensing system also showed a good selectivity of $\mathrm{Pb}^{2+}$ from many other metal ions, especially $\mathrm{Hg}^{2+}$.

Xuan and Park [92] presented a miniaturized and flexible electrochemical sensor incorporated with rGO and CNT composite working on a flexible gold substrate for metallic ions detection. $\mathrm{rGO}$ has been used in consequence to its high theoretical surface area and applicability for the production of electrochemical sensors and biosensors. However, the actual accessible surface area of electrodes based on rGO is much lower when compared to the theoretical surface area, due to the GPN sheets aggregation during processing. So, CNT has been applied between GPN sheets to prevent its agglomeration. The material chosen as electrode was bismuth (Bi), due to the need to have an environmentally friendly element. Sensor confection was based in coating silicon wafers with a polyimide film and a rGO/CNT layer (in two different amounts) or a rGO layer. The efficiency of the proposed sensor was tested by cyclic voltammetry, in electrochemical analysis of $\mathrm{Cd}$ and $\mathrm{Pb}$ ions. The developed sensor exhibited high rates for detection of the target metallic ions due to excellent properties of rGO/CNT layer and good pickling characteristics of $\mathrm{Bi}$. Furthermore, the sensor presented advantages in comparison with traditional sensors, such as large surface area of working electrode, good sensitivity, fast response time, and stability.

Menacer et al. [93] created a CNT-based sensor for acetone detection using finite elements and a neural network. They based their simulations on a resonator sensor system where the interaction of a molecule with the active sensor surface causes a shift of resonance frequency. Authors considered the influence of single-walled CNT structural parameters, such as chirality, length, diameter, and molecule arrangement onto the sensor surface. Results indicated that the natural frequency of $\mathrm{CNT}$ resonator decreased with the increasing of the number of acetone molecules and also that the frequency shift got larger with decreasing CNT length and with high chirality. This is a promising system because it can reach high sensitivity at a molecular level and is cheap compared to a similar sensor composed of boron nitride nanotube.

An overdose of caffeine can induce adverse side effects to consumers, for instance, oversensitivity, irritability, anxiety, and insomnia [94, 95]. Therefore, determining the concentration of caffeine in food samples is necessary to avoid involuntary excessive consumption of this compound. Lezi [39] fabricated a GPN/Nafion sensor to determine the presence of caffeine by adsorptive stripping voltammetry. They compared their results with a conventional highperformance liquid chromatography methodology. The limit of detection was $0.021 \mu \mathrm{mol}$, with a deviation of $2 \%$. Authors tested different types of samples as foods, beverages, pharmaceuticals, and human fluids. Citric acid, sucrose, $\mathrm{K}^{+}$, $\mathrm{Na}^{+}, \mathrm{Ca}^{2+}$, maltose, and $\mathrm{SO}_{4}{ }^{2-}$ at $0.1 \mathrm{mmol} / \mathrm{L}$ did not interfere with the determination of $1.0 \mu \mathrm{mol} / \mathrm{L}$ of caffeine. Table 2 presents a comparison between the results obtained by some 
TABLE 2: Comparison between some of the molecules and chemical elements sensor systems described in this review and different systems found in the literature.

\begin{tabular}{|c|c|c|c|c|}
\hline $\begin{array}{l}\text { Sensor compound } \\
\text { or device }\end{array}$ & $\begin{array}{l}\text { Sensitivity/linear } \\
\text { range/LOD }\end{array}$ & Great response for & Other reported systems & $\begin{array}{c}\text { Responses from } \\
\text { other systems }\end{array}$ \\
\hline $\begin{array}{l}\text { GPN onto } \\
\text { polyimide } \\
\text { subst. [84] }\end{array}$ & $\begin{array}{l}21.69 \mathrm{ppm} \\
\text { (river water, first } \\
\text { run) }\end{array}$ & $\mathrm{NO}_{3}-\mathrm{N}$ & $\begin{array}{l}\text { Laboratory-standard method UV-spectrometry } \\
\qquad[84]\end{array}$ & $\begin{array}{l}21.5 \text { ppm (river } \\
\text { water) }\end{array}$ \\
\hline rGO/Betec [37] & $1.1 \mu \mathrm{g} / \mathrm{L}$ & $\mathrm{NO}_{3}-\mathrm{N}$ & $\begin{array}{l}\text { Phenoldisulfonic acid method and ultraviolet } \\
\text { spectroscopy (photoabsorption at } 220 \mathrm{~nm} \text { ) [37] }\end{array}$ & $\begin{array}{c}0.02-2 \mu \mathrm{g} / \mathrm{L} \\
\text { and } 0.08-4 \mu \mathrm{g} / \mathrm{L}\end{array}$ \\
\hline $\begin{array}{l}\text { Electrode with } \\
\text { functionalized } \\
\text { CNT [86] }\end{array}$ & $\begin{array}{l}5 \times 10^{-8} \mathrm{M} \text { in } \mathrm{pH} \\
\text { range } 3.0 \text { to } 9.0\end{array}$ & $\mathrm{Cr}(\mathrm{III})$ & $\begin{array}{l}\text { Chromium carbon paste electrode sensor [96]; } \\
\text { aurin tricarboxylic acid modified silica [97] }\end{array}$ & $0.16 \mu \mathrm{M}$ to $1.0 \mu \mathrm{M}$ \\
\hline $\begin{array}{l}\text { Boron-doped } \\
\text { NDs [87] }\end{array}$ & $0.12 \mu \mathrm{M}$ to $0.43 \mu \mathrm{M}$ & $\begin{array}{c}\text { HQ; } \\
\text { 1,2-dihydroxybenzene }\end{array}$ & $\begin{array}{l}\text { Graphene-polyoxometalate [98]; GCE modified } \\
\text { with aspartic acid [99] }\end{array}$ & $0.05 \mu \mathrm{M}$ to $7.33 \mu \mathrm{M}$ \\
\hline GPN film [38] & 0.5 to $5.0 \mu \mathrm{g} / \mathrm{L}$ & $\mathrm{Cd}^{2+}, \mathrm{Pb}^{2+}$ and $\mathrm{Cu}^{2+}$ & $\begin{array}{c}\text { Screen printed CNT [100]; cyano groups } \\
\text { modified polymer [101] }\end{array}$ & $0.7 \mu \mathrm{g} / \mathrm{L}$ to $165 \mu \mathrm{g} / \mathrm{L}$ \\
\hline $\begin{array}{l}\text { GPN QD/Au } \\
\text { nanoparticles [91] }\end{array}$ & $\begin{array}{c}16.7 \mathrm{nM} \text { (detection } \\
\text { range } 50 \mathrm{~nm} \text { to } \\
4 \mathrm{mM} \text { ) }\end{array}$ & $\mathrm{Pb}^{2+}$ & $\begin{array}{l}\text { Organic dye [102]; semiconductor quantum } \\
\text { dots; GPN-QD/GO }\end{array}$ & $\begin{array}{c}0.09 \mathrm{nM}-0.6 \mathrm{nM} \\
\text { (detection range } 0.1 \\
\text { to } 435.0 \mathrm{nM} \text { ) }\end{array}$ \\
\hline GPN/Nafion [39] & $\begin{array}{l}0.021 \mu \mathrm{mol} . \mathrm{L}^{-1} \\
\quad\left(\mathrm{LOD}^{*}\right)\end{array}$ & Caffeine & $\begin{array}{l}\text { Chemical reduction of GO/CNTs [103]; } \\
\text { electrochemical reduction of GO/HDA [104] }\end{array}$ & $\begin{array}{c}0.02 \mu \mathrm{mol} \cdot \mathrm{L}^{-1}- \\
0.43 \mu \mathrm{mol} \cdot \mathrm{L}^{-1} \\
(\mathrm{LOD})\end{array}$ \\
\hline
\end{tabular}

${ }^{*} \mathrm{LOD}=$ limit of detection.

of the molecules and chemical sensors presented in this topic with other works previously reported (not discussed above).

\subsection{Physical-Property Sensors}

3.2.1. Humidity. Humidity can be defined as the amount of water vapor in a gas sample [105], which is a critical variable for laboratorial and industrial processes, agriculture, chemistry, food production and storage, semiconductors, textile, and pharmaceutic industry. Thus, for these processes, humidity control system is indispensable to obtain suitable results. In this context, simple and efficient methods to detect and quantify relative humidity have intensified in recent years [106].

GPN-like structures can be used as humidity sensors. Leng et al. [40] built up a humidity sensor using diamine modified GO mixed with Nafion polymer to form a hybrid film. Although satisfactory stability and linearity were occasionally reported in previous investigations, they achieved an increase of $10 \%$ on the long-term stability and linearity even after two months.

Li et al. [107] proposed a highly sensitive humidity sensor based on GO with uniformly dispersed MWCNT. In this study, MWCNTs were used as detection agents. Although van der Waals interactions can interfere on the efficiency of the carbonaceous material, GO was applied in the mixture to promote dispersion of MWCNTs. For developing the sensor, interdigitated electrodes (IDEs) were prepared. For this purpose, electrodes were fabricated on a $\mathrm{Si}$ wafer with a top layer of silicon dioxide $\left(\mathrm{SiO}_{2}\right)$ and $\mathrm{Ti} / \mathrm{Au}$ layers. After that, a sensing film of MWCNT/GO was deposited onto the substrate surface. For comparison, IDEs sensor with only GO film was prepared in the same way. Sensing properties of the humidity sensors were evaluated using saturated salt solutions. After tests, the authors proved that the sensor with MWCNT/GO film presented sensibility thirteen times higher compared to the sensor with GO alone. Besides that, MWCNT/GO sensors demonstrated fast response and recovery time.

Quartz crystal microbalance (QCM) is widely used as a humidity sensor, among different transducers types, because of its high resolution, low cost, and digital frequency output [108]. A QCM humidity sensor is usually produced from the deposition of a sensing film on its electrode $[109,110]$. This sensing film frequently consists of materials sensitive to humidity [111]. Yu et al. [111] reported a high-stability QCM humidity sensor coated with ND/MWCNTs hybrid film, committing it to obtain a rigid material with high mechanical modulus. The poor dispersion of CNTs was overcome by NDs incorporation $[111,112]$. Sensing ND/MWCNT film was produced through a mixture, in which MWCNT aqueous mixture was added in an ND suspension under ultrasonic treatment. Then, the QCM electrode was coated with the sensing film, and for comparison means, the QCM electrode was also coated with an ND-only film. The humidity measurement was divided into impedance analysis method and the oscillating circuit. For this purpose, humidity conditions were conducted by different kinds of saturated salt solutions. After tests, the sensor coated with ND/MWCNT sensing film presented higher stability and improved measurements with better resolution compared to the ND-based sensor [111].

In another study, Ding et al. [110] also described a QCM humidity sensor coated with $\mathrm{C}_{60} / \mathrm{GO}$. GO was applied in this study due to its large hydrophilic functional groups and because it improves the sensibility of QCM humidity sensors. However, the interaction with water molecules can increase the viscosity of GO film, which can damage the sensor. Thus, $\mathrm{C}_{60}$ formed some hydrophobic isolation layers between GO sheets, in addition to reducing its aggregation. 
The authors made a QCM with $\mathrm{C}_{60} / \mathrm{GO}$ and other using only GO to evaluate the proposed sensor. Deposition onto QCM electrode was obtained by the drop-casting method. QCM sensors were exposed to environments with different relative humidity, such as saturated salt solutions. After the evaluation, that $\mathrm{C}_{60} / \mathrm{GO}$-coated QCM humidity sensor was better than GO-coated QCM due to its dynamic response, recovery properties, and stability.

Saha and Das [113] used $\mathrm{C}_{60}$ FLN to create oriented nanopores in $\gamma$-alumina $\left(\mathrm{Al}_{2} \mathrm{O}_{3}\right)$ thick films to detect humidity in a gaseous environment. Porosity and surface area were characterized by scanning electron microscope, atomic force microscope, and Brunauer-Emmett-Teller. Electrical measurements were also performed to obtain sensitivity, response, recovery, and hysteresis. Results indicated that $\mathrm{C}_{60}$-modified $\gamma-\mathrm{Al}_{2} \mathrm{O}_{3}$ sensor was highly sensitive and capable to detect the presence of trace humidity in a gaseous environment with low pressure. The quasilinear response was very sharp and drift, with maximum linearity obtained at $1 \mathrm{kHz}$. In Table 3 is presented a comparison between the results obtained by some of the humidity sensors presented in this topic with other works previously reported (not discussed above).

3.2.2. Strain. Most of the applications of carbon nanostructures in mechanical sensors are related to strain measurements, and it takes advantage of the interesting electromechanical properties of such materials. Special attention has been paid to CNTs since they display both piezoresistive and piezoelectric behaviors under tension [118]. Due to these properties, CNTs have been used to develop sensors, generally by measuring the variation of electrical resistance or voltage of CNT composites when subjected to external action. The most significant development in strain sensors is concentrated on piezoresistive effects, mainly due to its stronger electromechanical effect in most CNT arrangements and composite matrices. Piezoresistive strain behavior in CNTs has been thoroughly exploited in sensors [119]. Gauge factors (ratio of relative change in electrical resistance to the mechanical strain) have been steadily increasing, leading to increased sensitivity. Also, advances in other desired sensing properties have been enhanced, such as stability and stretchability, the latter being a big hurdle in the development of conventional semiconductor-based sensors [120].

$\mathrm{Yu}$ et al. [121] demonstrated a high-performance strain sensor based on conductive styrene-butadiene-styrene (SBS) and CNT fiber prepared via wet-spinning. The sensors obtained presented a very high gauge factor of 175 at $50 \%$ deformation and wide workable range. The authors observed that SBS/CNT sensors still maintain flexibility and durability, characteristics of SBS polymer, which could lead to different applications in large deformation monitoring.

CNT-based strain piezoresistive sensors have been successfully applied in monitoring technology composites, with possible future applications into aerospace and automotive industries, mostly due to the increase of composites use by manufacturers. CNTs have its conductivity sharply decreased with an increase in deformation ratio, and this process is reversible. Exploiting this fact, Ma et al. [122] put forward a method for real-time strain/stress mapping in composites by measuring piezoresistivity and calculating electrochemical impedance change in a CNT yarn grid across the composite, with the advantage of not affecting its mechanical properties.

Unique characteristics of CNT structure demands extra care in sensors manufacturing and application. For instance, Arif et al. [123] demonstrated the strong sensitivity of the gauge factor to the strain rate in CNTs/polydimethylsiloxane (PDMS) composite sensors, showing that gauge factor increased under higher strain rate.

CNTs are also known to improve poling efficiency in piezoelectric composite sensors when used as additives. Zhao et al. [124] described the effects of CNT in cementsand-based piezoelectric composites ranging from 0 to 0.9 vol. \% of nanotubes. Piezoelectric coefficient $d_{33}$ increased six-fold from 0 to 0.6 vol. \% of CNTs content, decreasing sharply from 0.6 vol. \% onwards. Table 4 shows a comparison between CNT/PDMS sensor with the response of other works previously reported (not discussed above).

3.2.3. Pressure. Active development is taking place in the field of "skin-like" pressure sensors, in particular, applications in prosthetics and robotics. In such applications, structural flexibility, especially in association with sensors showing high sensitivity around and below $1 \mathrm{kPa}$, is sought after [127]. As in the case of strain sensors, pressure sensors function by relying upon piezoresistive or piezoelectric behaviors of the CNT-based material, measuring resistance or voltage across the sensor and calibrating the response as a function of the external stimulus. Sensor flexibility is usually achieved by using an elastomer such as PDMS as a structural material. Using microstructured MWCNT deposited by airspray coating over PDMS substrates, Li et al. [127] achieved an ultrahigh sensitivity of $-9.9 \mathrm{kPa}^{-1}$ at pressure levels below $100 \mathrm{~Pa}$ in flexible sensors. These sensors rely on the variation of CNT conductivity when subjected to external pressure.

Cost-effective CNT-PDMS wearable sensors were put forward by Gao et al. [128] using a sandpaper molding method. These sensors presented pressure detection range from $5 \mathrm{~Pa}$ to $50 \mathrm{kPa}$ with a stimuli-response time of $0.2 \mathrm{~s}$ and cycling stability of over 5000 cycles. Another important characteristic in prosthetics and robotics applications is the stretchability. In such way, Giffney et al. [129] reported MWCNT/silicone rubber composite strain sensor displaying stretching of up to $300 \%$ with retaining of $11 \%$ hysteresis after maximum strain, with gauge factors between 1.0 and 1.5 depending on composition.

Two-dimensional force sensors fabricated with patterned CNTs on PDMS nanocomposite were developed by da Costa and Choi[130]. Using inkjet printing followed by PDMS spin coating over a CNT network allowed a simple and efficient way of patterning a large area of flexible force sensors.

Piezoelectric effect-based pressure sensors also experienced significant improvements in recent years. Kim and Kim 
TABLE 3: Comparison between some of the humidity sensor systems described in this review and other systems found in the literature.

\begin{tabular}{|c|c|c|c|c|}
\hline $\begin{array}{l}\text { Sensor compound } \\
\text { or device }\end{array}$ & Sensitivity/linear range/LOD & $\begin{array}{l}\text { Great } \\
\text { response } \\
\text { for }\end{array}$ & Other reported systems & Responses from other systems \\
\hline $\begin{array}{l}\text { MWCNT/GO } \\
\text { (film) [107] }\end{array}$ & $\begin{array}{l}11 \% \text { to } 97 \% \text { (measured range) } \\
7980 \mathrm{pF} / \% \mathrm{RH}\end{array}$ & Humidity & $\begin{array}{c}\text { MWCNT [114]; GO film [107]; } \\
\qquad \mathrm{TiO}_{2}[115]\end{array}$ & $\begin{array}{l}0 \% \text { to } 98 \% \text { (humidity range) and } \\
0.63 \mathrm{pF} / \% \mathrm{RH} \text { to } 6000 \mathrm{pF} / \% \mathrm{RH}\end{array}$ \\
\hline $\begin{array}{l}\text { ND/MWCNTs (drop } \\
\text { casting-QCM) [111] }\end{array}$ & $\begin{array}{c}\text { Q factor: } 26560(11 \% \mathrm{RH}) \text { and } \\
23460(11 \% \mathrm{RH})\end{array}$ & Humidity & $\begin{array}{c}\text { PEG [116]; MWCNT [117]; GO/ } \\
\text { MWCNTs [117] }\end{array}$ & $\begin{array}{c}Q \text { factor: } \sim 12,000(11 \% \mathrm{RH}) \text { and } \\
1198(84.3 \% \mathrm{RH}) ; 12940(10 \% \\
\mathrm{RH}) \text { and } 6113(95 \% \mathrm{RH})\end{array}$ \\
\hline $\begin{array}{l}\mathrm{C}_{60} / \mathrm{GO} \text { coated } \\
\text { QCM }[110]\end{array}$ & $\begin{array}{l}31 \mathrm{~Hz} / \% \mathrm{RH} \text { (in the range } 11 \% \\
\text { to } 97 \% \mathrm{RH} \text { ) }\end{array}$ & Humidity & $\begin{array}{l}\text { QMA401* }^{*} \text { (trace moisture } \\
\text { analyzer) }[110] \text {; HMP155** } \\
\text { (HUMICAP }{ }^{\circledR} \text { humidity and } \\
\text { temperature probe) }[110]\end{array}$ & $2 \mathrm{mV} / \% \mathrm{RH}$ to $100 \mathrm{mV} / \% \mathrm{RH}$ \\
\hline
\end{tabular}

*Advanced Quartz Crystal Microbalance analyzer model QMA401. ** Vaisala HUMICAP® Humidity and Temperature Probe model HMP155.

TABle 4: Comparison between a strain sensor system described in this review and a different system found in the literature.

\begin{tabular}{|c|c|c|c|c|}
\hline $\begin{array}{l}\text { Sensor compound } \\
\text { or device }\end{array}$ & $\begin{array}{l}\text { Sensitivity/linear } \\
\text { range/LOD }\end{array}$ & $\begin{array}{l}\text { Great } \\
\text { response for }\end{array}$ & Other reported systems & Responses from other systems \\
\hline $\begin{array}{l}\text { CNT/PDMS } \\
\text { (solution mixing) [123] }\end{array}$ & $\begin{array}{l}\text { Gauge factor: } 8 \text { to } 47 \\
\left(\varepsilon^{*} 30 \% \text { to } 110 \%\right)\end{array}$ & Strain & $\begin{array}{c}\text { SWCNT/porous PDMS } \\
\text { (micropatterning) [125] } \\
\text { CNT-CB/PDMS } \\
\text { (solution mixing) [126]; }\end{array}$ & $\begin{array}{c}\text { Gauge factor: } 24 \text { to } 134 \\
(\varepsilon<40 \% \text { to } \varepsilon<160 \%) \\
0.91 \text { to } 13.1 \\
(\varepsilon<100 \% \text { and } 250 \%<\varepsilon<300 \%)\end{array}$ \\
\hline
\end{tabular}

${ }^{*} \varepsilon=$ strain range.

[131] reported a flexible $\mathrm{Pb}\left(\mathrm{Zr}_{1 / 2} \mathrm{Ti}_{1 / 2}\right) \mathrm{O}_{3^{-}}\left(\mathrm{Pb}\left(\mathrm{Zn}_{1 / 3} \mathrm{Nb}_{2 / 3}\right) \mathrm{O}_{3^{-}}\right.$ $\left.\mathrm{Pb}\left(\mathrm{Ni}_{1 / 3} \mathrm{Nb}_{2 / 3}\right) \mathrm{O}_{3}\right)$ ceramic-epoxy based on CNTs-doped sensor with high sensitivity and linear response from 12 to $120 \mathrm{kPa}$, achieving piezoelectric coefficients of $68 \mathrm{pC} / \mathrm{N}\left(d_{33}\right)$ and $434 \mathrm{mV} \cdot \mathrm{m} / \mathrm{N}\left(\mathrm{g}_{33}\right)$, enhancing the overall output voltage to $572 \mathrm{mV}$ under $1 \mathrm{~N}$.

Besides environmental controlling, GPN is also being used in piezoresistive equipment [132,133]; Dong et al. [132] proposed a simple approach to fabricate piezoresistive sensors based on the hierarchical structure of sea sponges and conductive composites networks of polydopamine rGO and silver nanowires to measure pressure. Sea sponge was used as a structure to maintain the form when the sensor was under strain-stress. On the other hand, silver enhanced conductivity and strain sensitivity. Results were positives: high sensibility $\left(0.016 \mathrm{kPa}^{-1}\right.$ at $\left.0-40 \mathrm{kPa}\right)$, fast response (less than $0.54 \mathrm{~ms}$ ), and good reproducibility (more than 7000 loading/unloading cycles). Some results are organized in Table 5, comparing them to the systems previously reported (not discussed above).

\subsection{Biosensors}

3.3.1. Drugs. Drug identification and quantification is an essential requirement to avoid overdoses and control illegal content and environmental contamination. Carbon-based sensors have also been developed and applied to drugs concerns. Nanocomposites based on CNTs, NDs, GPN, and FLN can be used to detect different licit and illicit drugs, including anticancer drugs as chlorambucil and flutamide, tuberculosis drugs as pyrazinamide, tranquilizers as diazepam, and illicit drugs as amphetamine and phenylpropanolamine [134].
Anticancer drugs are one of the most studied substances in pharmaceuticals. Sensors able to detect these drugs in human organisms are currently on focus. Prasad et al. [134] incorporated $\mathrm{C}_{60}$ FLN to enhance the conductivity and sensitivity of imprinted polymeric micelles used to detect chlorambucil (CHB), an anticancer drug. The electrochemical sensor was prepared using electroactive $\mathrm{C}_{60^{-}}$ monoadduct-micellar molecularly imprinted polymer grafted on ionic liquid-based carbon ceramic electrode (IL$\mathrm{CCE}$ ). The results showed that the presence of $\mathrm{C}_{60}$-monoadduct significantly accelerated the electron transfer process to the IL-CCE, presenting fast electrode kinetics and high analyte diffusivity. According to the authors, the work revealed the potential of FLN as nanomediator in the signal transduction, being used as selective recognition of $\mathrm{CHB}$ in aqueous and real samples.

Functionalized MWCNT-based sensor for flutamide (another anticancer drug) detection was developed by Farias et al. [135]. As reported, flutamide overdose can induce hepatitis, which makes necessary the monitoring of this drug. A noninvasive flutamide monitoring system was created and applied by the aforementioned authors, detecting the drug in pharmaceutical samples and artificial urine samples. Such system was prepared by placing MWCNT functionalized with $-\mathrm{OH},-\mathrm{COOH}$, and $=\mathrm{O}$ onto a glassy carbon electrode. The sensor presented excellent results for response concentration (from $0.10 \mu \mathrm{mol} \cdot \mathrm{L}^{-1}$ to $1000 \mu \mathrm{mol} \cdot \mathrm{L}^{-1}$ ), limits of detection $\left(0.03 \mu \mathrm{mol} \cdot \mathrm{L}^{-1}\right)$, quantification $\left(0.10 \mu \mathrm{mol} \cdot \mathrm{L}^{-1}\right)$, and high sensitivity of $0.30 \mu \mathrm{A} \cdot \mu \mathrm{mol}^{-1} \cdot \mathrm{L}$. MWCNT exhibited effective catalytic ability to oxidize or reduce the analyzed drug.

NDs were used to modify a glassy carbon electrode (NDGCE), for detection of pyrazinamide (PZA), by Simioni et al. [136]. PZA is one of the most adopted antibiotics to treat tuberculosis, and its level in biological fluids must be 
TABLE 5: Comparison between pressure sensor systems described in this review and those found in the literature.

\begin{tabular}{|c|c|c|c|c|}
\hline Sensor compound or device & $\begin{array}{l}\text { Sensitivity/linear } \\
\text { range/LOD }\end{array}$ & $\begin{array}{l}\text { Great } \\
\text { response for }\end{array}$ & Other reported systems & $\begin{array}{c}\text { Responses from } \\
\text { other systems }\end{array}$ \\
\hline MWCNT/PDMS subst. [127] & $-9.95 \mathrm{kPa}^{-1}$ & Pressure & Unstructured sensor [127] & About $-0.1 \mathrm{kPa}^{-1}$ \\
\hline CNT-PDMS wearable sensors [128] & $5 \mathrm{~Pa}$ to $50 \mathrm{kPa}$ & Pressure & Lithography method [128] & mes lower \\
\hline $\begin{array}{l}\text { Ceramic-epoxy/CNTs-doped } \\
\text { nanocomposite [131] }\end{array}$ & 12 to $120 \mathrm{kPa}$ & Pressure & Ceramic-epoxy nanocomposite [131] & Up to 2.5 times lower \\
\hline
\end{tabular}

rigorously managed to accomplish the desired therapeutic effects on patients. With this purpose, the authors developed an ND-GCE electrochemical sensor for PZA detection. Electrochemical features of the obtained ND-GCE were examined using a redox probe, and results revealed that ND was able to enhance the electrochemical features of the bare GCE. Concerning the electrochemical detection of PZA, improved PZA voltammetric response was achieved using the ND-GCE. Biological urine and human serum samples were examined, and significant recovery percentages were collected in the PZA determination.

Ahmadi et al. [137] theoretically studied the interaction of FLN with 16 different drug systems using DFT calculations. Adsorption energies, HOMO and LUMO energy levels, energy gap, chemical hardness, electrophilicity, and dipole moments were investigated. FLN was considered a promising material to be used as an electroactive sensor, since it presented a strong interaction with the following drugs: methyldopa, dextroamphetamine, tyramine, tolazoline, enalapril, and metoprolol. Similar work was performed by Parlak and Alver [138]. The authors used DFT calculation to study pristine and $\mathrm{B}, \mathrm{Al}, \mathrm{Si}, \mathrm{Ga}$, and Ge-doped $\mathrm{C}_{60}$ FLN as a sensor for amantadine detection. Doped FLNs were sensitive to the presence of amantadine, being the sample doped with B more efficient than the other systems.

FLNs have also been used as sensors for the detection of illicit drugs due to the increasing abuse of these substances. One of the most popular drugs used nowadays is the amphetamine (AA), requiring great attention by the police and drug communities. Bashiri et al. [139] studied the interaction of AA with pristine $\mathrm{C}_{60} \mathrm{FLN}$ and also $\mathrm{C}_{60}$ doped with $\mathrm{B}, \mathrm{Al}$, $\mathrm{Ga}, \mathrm{Si}$, and $\mathrm{Ge}$ using DFT. Although pristine $\mathrm{C}_{60}$ showed good sensitivity to AA, the weak interaction between them limits $\mathrm{C}_{60}$ use as an AA drug sensor. Replacing carbon atoms with other elements, especially $\mathrm{Si}$ and $\mathrm{Ge}$, significantly improved the reactivity and the sensibility of doped $C_{60}$ to AA drugs. In contact with AA, the work function of these sensors decreased, increasing the electron emission from their surfaces and emitting an electronic signal.

Moradi et al. [140] also used DFT to investigate the electronic sensitivity and reactivity of pristine, Al- and Sidoped $\mathrm{C}_{60}$ FLNs to the phenylpropanolamine drug (PPA). The authors obtained similar results observed by Bashiri et al. [139]. Pristine $\mathrm{C}_{60}$ presented good sensitivity, but weak interaction with PPA. The Al-doping increased the reactivity of $\mathrm{C}_{60}$ with PPA, but the electronic sensitivity decreased. On the other hand, Si-doped $\mathrm{C}_{60}$ showed an increase in both reactivity and electronic activity. In this case, the conductivity increased considerably, which can be converted to an electrical signal.
Rahimi-Nasrabadi et al. [141] presented a sensor-modified electrode with $\mathrm{CNT}, \mathrm{C}_{60}$, and 1-butyl-3-methylimidazolium tetrafluoroborate ionic liquid (IL) for diazepam determination on real samples, like serum, urine, and tablets. CNT was applied in this work to improve the dispersion of $\mathrm{C}_{60}$. Moreover, IL was used in presence of CNT because it retains its mechanical, electrical, and thermal properties, improving solubility and conductivity properties of ILs. For the tests, the authors used a system with three electrodes. The experimental part was based on simple solution mixing method. MWCNT and $\mathrm{C}_{60}$ were dispersed at first and then mixed with IL. Posteriorly, this mixture was immobilized in the working electrode. The results showed that the sensor had great selectivity and could detect diazepam in tablets, urine, and serum samples, additionally presenting good reproducibility and repeatability. Table 6 presents a comparison between some drug sensor reported by this review and other previously reported (not discussed above).

3.3.2. Biomolecules. Ways to control and monitor health problems have attracted extensive attention, and even more economic resources have been designated to new technologies researches and development. The faster the changes on the organism function are detected, the more effective their control will be. Furthermore, diagnosis systems with low detection limit, which means more sensitivity, increases the possibilities of medical intervention on disease treatment more efficiently. In this way, devices for biomolecules detection and quantification are of great importance to improve life quality.

Several examples of high-quality carbon nanostructuredbased sensor for biomedical applications can be found in the literature. FLN, GPN, and CNT/GPN hybrid sensors have been used for monitoring of nonenzymatic glucose for diabetes diagnosis. Sutradhar and Patnaik [30] developed a new biosensor using 3-amino-capto-1,2,4-triazole functionalized $\mathrm{C}_{60}$-based gold nanocomposite for nonenzymatic sensing of glucose. Theoretical DFT calculations showed the potential of the composite for effective electron transport via drastic reduction of HOMO-LUMO gap. Experimental results confirmed the theoretical studies since the electrochemical oxidation of glucose was favored by the large surface area of the new composite. Besides that, cyclic voltammetry and amperometry revealed excellent electrocatalytic activity. In summary, this glucose biosensor presented good selectivity and stability, being a potential material for diabetes diagnosis.

Wei et al. [147] made a GPN/Au-enhanced plastic clad silica fiber optic surface plasmon resonance (SPR) sensor to 
TABLE 6: Comparison between some of the drugs sensor systems described in this review and those already reported in the literature.

\begin{tabular}{|c|c|c|c|c|}
\hline Sensor compound or device & $\begin{array}{l}\text { Sensitivity/linear } \\
\text { range/LOD }\end{array}$ & $\begin{array}{l}\text { Great } \\
\text { response for }\end{array}$ & Other reported systems & $\begin{array}{l}\text { Responses from } \\
\text { other systems }\end{array}$ \\
\hline $\begin{array}{l}\mathrm{C}_{60} \mathrm{FLN} / \mathrm{imprinted} \\
\text { polymeric micelles [134] }\end{array}$ & $\begin{array}{c}1.47 \text { to } 247.20 \mathrm{ng} \cdot \mathrm{mL}^{-1}(\mathrm{LOD} \\
\left.0.36 \mathrm{ng} \cdot \mathrm{mL}^{-1}\right)\end{array}$ & $\mathrm{CHB}$ & $\begin{array}{l}\text { SDS-monoadduct-micellar MIP/ } \\
\text { IL-CCE [134] }\end{array}$ & 6.4 times lower \\
\hline $\begin{array}{l}\text { Functionalized MWCNT } \\
(-\mathrm{OH},-\mathrm{COOH} \text { and }=\mathrm{O})[135]\end{array}$ & $0.30 \mu \mathrm{A} \cdot \mu \mathrm{mol}^{-1} \cdot \mathrm{L}$ & Flutamide & $\begin{array}{c}\text { Nano-Ag/MGCEs [142] } \\
\text { CTAB/CPE* }[143]\end{array}$ & $\begin{array}{r}4.5 \times 10^{-6} \mu \mathrm{A} \cdot \mu \mathrm{mol}^{-1} \cdot \mathrm{L} \\
9.08 \times 10^{-3} \mu \mathrm{A} \cdot \mu \mathrm{mol}^{-1} \cdot \mathrm{L}\end{array}$ \\
\hline ND-GCE [136] & $2.2 \times 10^{-7} \mathrm{~mol} \cdot \mathrm{L}^{-1}(\mathrm{LOD})$ & Pyrazinamide & MWCNT/GO/GCE [144] & $5.54 \times 10^{-6} \mathrm{~mol} \cdot \mathrm{L}^{-1}$ \\
\hline $\begin{array}{l}\text { CNT-C }{ }_{60} \text {-IL (modified GCE) } \\
{[141]}\end{array}$ & $0.087 \mu \mathrm{M}(\mathrm{LOD})$ & Diazepam & $\begin{array}{l}\text { Lead film electrode [145] and } \\
\text { screen-printed electrode [146] }\end{array}$ & $\begin{array}{c}0.002 \mu \mathrm{M} \text { to } 6.638 \mu \mathrm{M} \\
\text { (LOD) }\end{array}$ \\
\hline
\end{tabular}

${ }^{*} \mathrm{CTAB}=$ cetyltrimethylammonium bromide; $\mathrm{CPE}=$ carbon paste electrode.

measure a standard glucose solution, which represents a potential use for other biomolecules. When the target glucose molecule was adsorbed by the GPN, its permittivity changed inducing a variation of the refractive index on the sensing region. The effectiveness of this sensor can be associated with the large surface area of GPN. The sensibility of GPN-based fiber optic SPR sensor was more than twice bigger the one with the conventional gold film SPR fiber optic sensor. Furthermore, the sensor exhibited a fast response (5 s) and excellent reusability (3.5\% of fluctuation).

Building hybrid sensors may be an alternative to accomplish the desired sensing features. Jeong et al. [148] proposed a nonenzymatic sensor for glucose detection based on CNT and GPN nitrogen-doped such as a 3D opened macroporous network to immobilize gold $(\mathrm{Au})$ nanoparticles. Au nanoparticles were used because of their high sensitivity for detecting glucose. Detection of glucose was measured using a three-electrode electrochemical cell, the working electrode, reference electrode, and counter electrode. Electroactive surface area and charge transfer resistance of the modified electrodes were studied by cyclic voltammetry $(\mathrm{CV})$ and electrochemical impedance spectroscopy (EIS). After tests, it has been proved by the authors that the proposed sensor exhibits high sensitivity, an extremely low detection limit, and excellent selectivity and stability.

Nucleic acid sensing materials have been extensively studied for medical diagnosis allowing planning strategies and early treatment for diseases. Liu et al. [149] developed a new sensor for rapid and highly sensitive DNA detection based on the fluorescence-quenching properties of molecular Beacon made of QDs by $\mathrm{C}_{60}$ FLN carried by magnetic particles (MB@MNP). These nanosensors were dispersed in analytes solution for DNA capture leading to short-distance diffusion of targets to the sensor surface. Then, nanosensors were concentrated to a substrate by a magnetic force to amplify fluoresce signal for target quantification. Highdensity MB@MNP probes amplified detection signal by 5-10 times, resulting in a low limit of detection. High selectivity, rapid sensitivity, and label-free detection method of MB@MNP probes enable their use as low-concentration DNA sensors.

Li et al. [150] developed an FLN-based biosensor for ultrasensitive adenosine triphosphate (ATP), an essential biomolecule responsible for cellular metabolism. The biosensor was composed of n-type $\mathrm{C}_{60}$-decorated $\mathrm{Au}$ nanoparticle @
$\mathrm{MoS}_{2}\left(\mathrm{C}_{60} \mathrm{Au} \mathrm{NP} @ \mathrm{MoS}_{2}\right)$ as a signal indicator and a p-type $\mathrm{PbS} \mathrm{QD}$ as an efficient signal quencher. $\mathrm{MoS}_{2}$ was used to modify $\mathrm{C}_{60}$ band gap to increase the photocurrent conversion efficiency and form an ideal photoelectrochemical signal indicator. The analysis showed that by combining $\mathrm{C}_{60} \mathrm{Au} \mathrm{NP} @$ $\mathrm{MoS}_{2}$ and PbS QD, higher sensitivity was achieved. According to the authors, the designed biosensor has great potential to detect ATP at ultralow levels (detection limit of $3.30 \mathrm{fM}$ ). Recent works have shown the design of sensors for L-histidine [32], prostate antigen [151], proteins [152, 153], biomarkers $[154,155]$, and several others biomolecules [156-159].

CNT field-effect transistors (CNTFET) have been successfully implemented in DNA sensors. Tran et al. [160] reported detection of influenza A virus using a CNTFETbased DNA sensor, achieving a limit of detection of $1 \mathrm{pM}$ in a linear range from $1 \mathrm{pM}$ to $10 \mathrm{nM}$. Dudina et al. [161] reported the development of biosensor platform through an array of 9216 CNTFETs, measuring resistance in the $50 \mathrm{k} \Omega$ to $1 \mathrm{G} \Omega$ range, achieving a noise performance of $2.14 \mathrm{pA}_{\mathrm{RMS}}$ at a $1 \mathrm{kHz}$ bandwidth and $0.84 \mathrm{pA}_{\mathrm{RMS}}$ at a $1 \mathrm{MHz}$ bandwidth.

NDs, as well as CNTs, can be similarly modified to be incorporated in nanocomposites for biological applications. However, NDs are optically transparent in the UV/ Vis and IR regions of the electromagnetic spectrum [4], besides having other exceptional properties. For this reason, they are considered to be better candidates than commonly used nanomaterials for application in biological systems [6]. The aforementioned outstanding properties of NDs along with their biocompatibility attract much interest of researchers. According to Zheng et al. [9] it is necessary to focus on solving two critical issues to properly take advantage of the remarkable properties of FNDs. The first one is the colloidal stability of NDs, once particles need to be stable in biological fluids, and the second is the ability to be taken up by cells, improving the dispersion of particles. In their study, the authors reported physical adsorption of a polypeptide, which could address both mentioned problems, besides preserving the material's properties, as photoluminescence, magneto-optical properties, and biocompatibility, concluding that these peptide-coated NDs are promising candidates to be used as intracellular magnetosensitive nanosensors.

To employ their potential for intracellular utilization, FNDs have to be in contact with cellular media, and as previously stated, particles must be dispersed to have an 
optimal sensitivity. Hemelaar et al. [28] showed that some proteins and salts spontaneously adhere to FNDs and may cause aggregation, what would reduce the chances of having a single FND taken up inside a cell. In the paper, some strategies to prevent agglomeration in Dulbecco's Modified Eagle Medium are discussed. The best result was achieved coating FND with Fetal Bovine Serum (FBS), before adding them to a salt-rich solution. In this case, the size of resulting particle decreased, due to restriction of interactions between different protein-diamond aggregates.

In a subsequent study, Hemelaar et al. [162] evaluated the response of HeLa cells to FNDs uptake, investigating whether nanoparticles affect cell biology and formation of reactive oxygen species (ROS). To prevent samples from aggregation, they used the previously cited method, treating them with FBS. Four different FNDs were tested, changing size and shape, number of NV centers, diameter, and surface potential. Different sizes and shapes of FNDs did not change ingestion, and there was no selection process during cell division and no excretion of particles. Cell viability after FNDs uptake was not altered for any of the samples, indicating that, in general, FND does not negatively influence total free radical level inside the cell. This research also showed potential for magnetic resonance measurement purposes through the internalization of tens of FNDs into HeLa cells, but in this case, just one FND would be enough.

Simpson et al. [163] evaluated FNDs as probes for intraneuronal temperature mapping. In the first stage of this study, the electrophysiological effects of FNDs with $170 \mathrm{~nm}$ and about $500 \mathrm{NVs}$ per particle were tested in primary cortical neurons. Multielectrode arrays (MEA) showed no neurotoxicity in 25 separate parameters adding nanodiamonds at different concentrations over distinct periods. In the second stage of the research, the authors demonstrated enhanced signal to background fluorescence imaging and applied quantum control techniques on temperature mapping from thousands of FNDs probes simultaneously in a neuronal network. All tests showed that FNDs are promising candidates for multimodal imaging in biology and that they can work as active multimodal sensors in neuronal networks.

Polyaniline (PANI) shows remarkable electrochemical properties and was used in the study of Kumar et al. [164] for urea sensing, considering that high urea levels in cattle can influence fertility and be an indicator of pathological problems. Moreover, excess of urea in milk may cause several health issues. A hybrid graphitized ND (GND)/PANI nanocomposite was developed via interfacial polymerization for urea sensing. This sensor was capable of working without electrolyte solutions or large quantities of analyte. Hybrid GND/PANI sensor was three times more effective than bare PANI sensor. Besides that, the experimented material could be used 25 times and measurements were easy, reproducible, and stable.

FND hybrid sensor consisting of an organic fluorescent probe bound to the surface of an NV nanodiamond was reported by Purdey et al. [165]. This new material was developed to be used as organic fluorescent probes for photostable imaging and detection of hydrogen peroxide, labeled peroxynanosensor (PNS). PNS revealed resultant fluorescence response equivalent to $\mathrm{H}_{2} \mathrm{O}_{2}$ concentration, and ND fluorescence remained constant over the concentration range examined. Authors asserted that PNS is viable for long-term confocal microscopy investigations within macrophage cells, as $\mathrm{H}_{2} \mathrm{O}_{2}$ sensing is not changed by repeated imaging of $\mathrm{NV}$ nanodiamond element. Besides that, PNS showed to be proper for monitoring $\mathrm{H}_{2} \mathrm{O}_{2}$ generation during cell proliferation and differentiation and spectrally compatible with stains for hyperspectral imaging. In Table 7 is presented a comparison between some of the responses for biomolecules presented in this topic and those already reported (not discussed above).

Zhang et al. [169] proposed the employment of stimulusresponsive hydrogels as a spacing transducer in between an ND with NV centers and magnetic nanoparticles (MNPs) intending to enable the use of ND with $\mathrm{NV}$ centers to measure biochemical parameters applying diamond quantum sensing. ND was adopted as core, with a shell of hydrogel and MNPs coating on the surface. The hydrogel could be managed to be sensitive to a chosen parameter. With a stimulus, volume phase transition of hydrogel would change and end in shifts in separation distance between the MNPs and ND, which would modify the detection of NV centers. For this specific study, authors have chosen poly $(N-$ isopropylacrylamide) (pNIPAM) as the hydrogel, and they carried out temperature sensing to illustrate enhanced sensibility, good reversibility, and stability of the sensor. This hybrid sensor was tested and showed to be suitable for detection of biochemical parameters, such as glucose, $\mathrm{pH}$, and enzyme.

Another two examples that do not refer to biomolecules' detection, but describe the quantum sensing mechanism is important to highlight. Ong et al. [29] studied the geometry of FNDs, with an average hydrodynamic diameter of $25 \mathrm{~nm}$ and flake-like geometry. FNDs revealed to have an aspect ratio higher than 5 and the flat faces of FNDs were oriented along the [110] or an equivalent zone axis. Estimating the shape of FNDs was stated to be especially relevant because it could affect the partial volume where NV centers could exist and the sensitivity of FND due to the position of NV centers, and relaxation time. A notable variation can be presumed from changing particle's shape from spherical to flake-like, as nearby spins have great contribution.

Influence of diamond surface chemistry on the quantum coherence of NV centers in NDs was studied by Ryan et al. [170], considering that functionalizations may affect quantum properties of NV center. The authors pointed out that reducing $\mathrm{sp}^{2}$ atoms in the ND surface reduces spin noise, once double-bonded carbon species are a predominant source of spin noise for near-surface NV centers. The borane reduction, usually the first step in functionalization, could on average double spin relaxation time of individual NV centers in NDs when confronted with thermally oxidized surfaces. For each specific functionalization is essential to comprehend the effect of functional group on the quantum properties, to have satisfying results using functionalized NDs as quantum probes.

In Figure 2 is summarized a graphical representation of the sensors system reported throughout this review. 
TABLE 7: Comparison between some of the biomolecules sensor systems described in this review and those already reported.

\begin{tabular}{|c|c|c|c|c|}
\hline $\begin{array}{l}\text { Sensor compound } \\
\text { or device }\end{array}$ & $\begin{array}{l}\text { Sensitivity/linear } \\
\text { range/LOD }\end{array}$ & $\begin{array}{c}\text { Great } \\
\text { response for }\end{array}$ & Other reported systems & $\begin{array}{l}\text { Responses from } \\
\text { other systems }\end{array}$ \\
\hline GPN/Au-SPR [147] & $7.01 \mathrm{~nm} /(\mathrm{mg} / \mathrm{ml})$ & Glucose & Sensor only coated with $\mathrm{Au}$ [147] & $2.98 \mathrm{~nm} /(\mathrm{mg} / \mathrm{ml})$ \\
\hline${\mathrm{QD}-\mathrm{C}_{60}[149]}$ & $100 \mathrm{fM}(\mathrm{LOD})$ & DNA & MB-based DNA detection [166] & $4.4 \mathrm{nM}$ to $8.5 \mathrm{nM}(\mathrm{LOD})$ \\
\hline CNTFET [160] & $1 \mathrm{pM}(\mathrm{LOD})$ & Influenza A & NR & $\mathrm{NR}$ \\
\hline GND/PANI [164] & $381.5 \mu \mathrm{A}\left(\mathrm{mg} \cdot \mathrm{mL}^{-1}\right)^{-1} \mathrm{~cm}^{-2}$ & Urea & $\begin{array}{c}\text { Zinc oxide-chitosan-urease [167] } \\
\text { Multilayered graphene [168] }\end{array}$ & $\begin{array}{c}0.13 \mu \mathrm{A} \cdot \mathrm{mM}^{-1} \cdot \mathrm{cm}^{-2} \\
5.43 \mu \mathrm{A} \cdot \mathrm{mg}^{-1} \cdot \mathrm{dL} \cdot \mathrm{cm}^{-2} \\
\end{array}$ \\
\hline
\end{tabular}

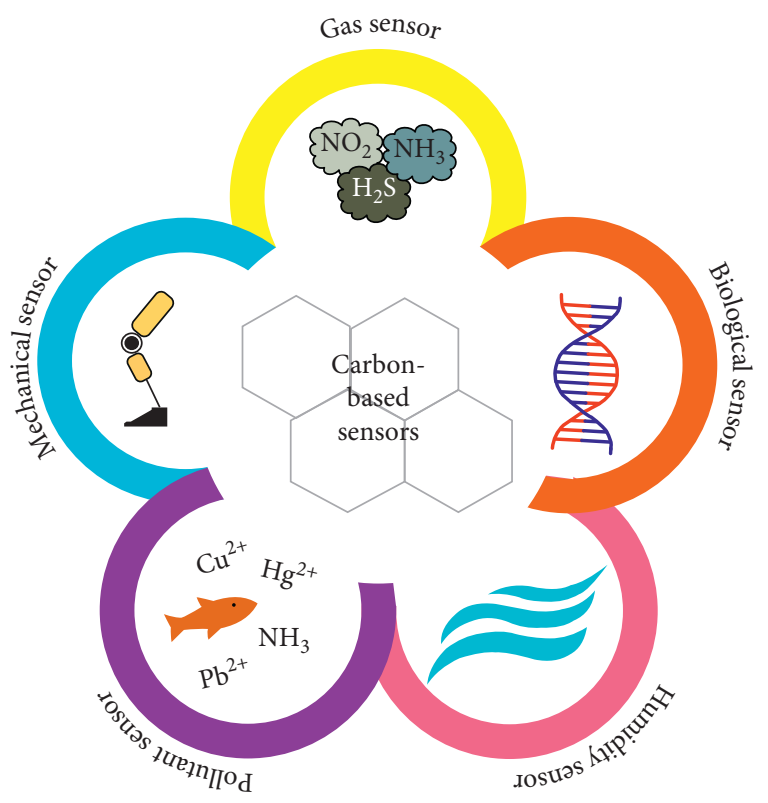

FIGURE 2: Graphical representation of the sensor systems reported throughout this review.

3.4. Limitations. Carbon nanostructures are versatile due to their physicochemical characteristics. However, they have some limitations in their application due structural characteristics and properties, such as functionalization, defects, and particles aggregation [171]. All of these examples of limitations are related to sensor system responses and can decrease the quality of the device. This topic will present some limitations for the carbon nanostructures discussed previously in this paper.

One of the critical challenges to exploit NDs properties is to control their surface chemistry. If ND particles are smaller than $5 \mathrm{~nm}$, almost $20 \%$ of the atoms are in the surface [8]. It implies that the properties of NDs are mainly determined by their surface. The interactions between the surface and bulk are an essential factor and therefore the interaction between the electrode surface and the analyte also plays an important role for better performances. The best surface characteristic should be determined according to the analyte of interest $[4,5]$. The surface terminations will also impact on the stability of NDs, once they may be individual NDs or clusters of NDs. In many applications is necessary to disaggregate NDs clusters into individual particles to take full advantage of NDs properties, because the size of aggregated or individual ND is suitable for each application; for example, aggregates of $100 \mathrm{~nm}$ can form photonic structures and diffract light, but for drug delivery are desired much smaller particles [10]. However, bulk nanodiamonds contain fewer impurities and defects than NDs, which leads to narrower spin resonance and better spin coherence duration [172]. In this way, it is important to determine the surface chemistry of the ND that regards as the functionalization as the NV luminescence and quantum properties [170]. One more task must be taken into consideration when working in a solution, for example, using biological fluids. In such case, ND particles need to be stable, i.e., they must not move or rotate, which would limit resolution and quantum sensing performance [9].

Influence of diamond surface chemistry on the quantum coherence of NV centers in NDs was studied by Ryan et al. [170] who considered that functionalizations may affect quantum properties of NV center. The authors pointed out that reducing $\mathrm{sp}^{2}$ atoms in the ND surface reduces spin noise, once double-bonded carbon species are predominant source of spin noise for near-surface NV centers. The borane reduction could, on average, double spin relaxation time of individual NV centers in NDs when confronted with thermally oxidized surfaces. For each specific functionalization is essential to comprehend the effect of functional group on the quantum properties yielding satisfying results using functionalized NDs as quantum probes. Some previous works have suggested, apart from borane reduced surfaces, fluorinated surfaces [173].

Despite the outstanding properties of FLNs, such structures present some disadvantages regarding their application as sensors systems. These disadvantages are related to their fabrication process, such as high-cost production and necessity of purification. Most of the techniques for FLN manufacture results in a mixture of different stable FLNs $\left(\mathrm{C}_{20}, \mathrm{C}_{60}, \mathrm{C}_{70}\right.$, among others) simultaneously and impurity molecules. Since the photophysical properties of FLN derivatives are very different, which can reduce the repeatability and stability of the sensor, the manufacture process to obtain such structure demands a step for separation and purification $[14,174,175]$.

Aggregation is one of the main problems faced during the production of sensors. Usually, FLNs are incorporated in a hybrid layer, forming FLN clusters. In this way, only a small fraction of individual FLN interacts with other phases/ materials, reducing the surface accessibility and, consequently, the sensor sensibility [58]. Two main strategies to overcome this problem are (i) to use new advanced architecture substrates [58] and (ii) to perform surface treatment of FLNs to improve their dispersion [16]. The surface modification (functionalization) is a common technique 
used in different nanoparticles. Besides the improvement in the dispersion for the production of hybrid sensors, functionalization of FLN with appropriate groups can also increase their solubility in water, enhancing their biocompatibility $[134,137,138,151]$. In addition, the sensitivity towards several molecules [139] can also be improved, as long as the charge recombination in the sensor [32].

FLNs also present some limitations related to their application for gas detection. The lack of selectivity between different types of gases that sometimes adsorbs each other, slow response time, influence of humidity level in the calibration, and also, instability of the sensor after several exposures to the air are examples of limitations that have to be overcome to improve FLN-based sensor sensibility [176].

CNT-based sensor application can be limited due some of its structure characteristics. CNTs cannot be applied directly in biomedical applications due their metallic characteristic, being insoluble in many solvents [177]. This characteristic can be a problem depending on the type of sensor for biological concerns, which is being developed. Also, CNT sizes obtained from the synthesis usually are not homogeneous, which can lead one to obtain results that are not reproducible [177].

CNT can be used as CNT-based biosensors operating with a field-effect transistor configuration (CNT-bioFET) to detect biomolecules. Although this type of system presents superior performance, the presence of background noise of electrostatic nature can phase out the reliable data being measured. As pointed out by Camilli and Passacantando [178], the noise has the same scale range of the signal, and its origin is associated to substrate interactions and surface adsorbates. Another concern is the presence of defects in CNT structure and even the functionalization method used for CNT application. They can influence CNT Young's modulus, which can yield several problems for sensor devices based on CNT specially those ones used to measure stress and strain properties [179].

Remaining disadvantages in using GNP-based sensors must be discussed [180]. These types of sensors are susceptible to oxidative environments [180], which could compromise their detection performance. Oxides onto the GPN surfaces could influence their electronic and chemical properties, affecting the sensor response [181]. In this case, a careful characterization is fundamental to guarantee sensor efficiency. Presence of multilayers in GPN sheets leads to interlayer sliding, resulting in different crack densities [182]. Besides, the cytotoxic limitations in GPN-based sensors remain unknown, which limited their utilization in biosensing applications [183].

Another limitation is related to defects in the GPN structure. Point defect that modifies the structure may change electromechanical properties [182], affecting sensor response and producing unreliable data. These defects can be due to GPN sp ${ }^{2}$ hybridizing property that induces formation of nonhexagonal structures [182] or due the type of manufacture process. Even CVD, that is one of the most used processes to produce GPN, grows a noncontinuous GPN layer, but rather a heterogeneous sheet with graphitic islands [184]. At least, there are still some difficulties in the production of GPN that could limit their sensors production, for instance, the lack of reproducibility to produce high-quality thin films and the difficulty to control uniformity of thickness in bilayer/trilayer GPN [185].

The carbon nanostructures-restricted dispersibility can compromise the material processing, once nanoscale particles have a strong tendency to interact with each other, due to the active van der Waals forces influence, which contribute to the formation of aggregates [186]. In order to minimize such adverse conditions, processes involving the carbon nanostructures hybridization are employed, aiming to improve their dispersion. One example is related to electrochemical sensor. The performance related to this type of sensor depends on the working electrode surface area, and that property is closely related to the good dispersion of the sensor constituents [92]. In this sense, many studies involving the hybrid carbon nanostructures used for application in sensors systems have addressed the dispersion theme, due to the interactions between such structures. $\mathrm{Li}$ et al. [107] presented GO as surfactant to disperse CNTs and $\mathrm{Yu}$ et al. [111] used ND to promote dispersive effect on CNTs. In another study, ND particles were applied to promote the GO dispersion [23]. Xuan and Park [92] added CNTs to act as spacers between the GPN sheets, thus avoiding their aggregation. In this way, the carbon nanostructures applicability limitation to sensors, caused by the agglomerate's formation, can be attenuated by the hybrid nanomaterials construction.

\section{Conclusions}

Carbon nanostructure-based sensors are systems with outstanding properties, presenting several possibilities of application. In this review, the versatile properties of these materials applied as sensor devices were presented. Different carbon allotropic forms can be used in several sensor fields with a response as good as for those devices already reported. Nanodiamonds, fullerenes, graphenes, nanotubes, and hybrid structures have been extensively used due to their electric, thermal, mechanical, and chemical high-quality properties. As reported by this review, carbon nanostructures have a high degree of selectivity, especially when functionalized. Nanodiamond is an excellent example of carbon structure that has been applied in the biological context (biosensor) because of nitrogen vacancies' centers that yield fluorescence responses. Fullerenes, because of their cage structure, high reactivity, and biocompatibility are applied in sensor systems that favor interactions (chemical and biological) between the device and the analyte. Newly reported sensor devices, using fullerenes, allowed the detection of DNA, chlorambucil, and diazepam samples.

Although carbon nanotubes have high reactivity like the other allotropes, their mechanical properties also imply in the development of sensors for physical parameter detection, such as stress and strain. Their high surface-to-volume rate also allows the development of gas sensors as good as those produced using graphene structure. The devices reported throughout this review represent the utmost development found nowadays for carbon nanostructure-based sensors, 
presenting the main research areas being explored and the potentialities for the future. Many remained challenges regard on the carbon-based manufacture to phase out contaminants as well as to improve the functionalization process. Improving these aspects will increase the sensor selectivity and control defect densification, which is strictly related to physical and chemical properties that must be overcome.

\section{Conflicts of Interest}

The authors declare that they have no conflicts of interest.

\section{Acknowledgments}

The authors gratefully acknowledge the financial support provided by the Sao Paulo Research Foundation (FAPESP) and Coordination for the Improvement of Higher Education Personnel (CAPES) (grant no. 88882.161936/2014-01-ITA/ PD 5/2014-9).

\section{References}

[1] S. Mehdi Aghaei, M. M. Monshi, I. Torres, S. M. J. Zeidi, and I. Calizo, "DFT study of adsorption behavior of $\mathrm{NO}, \mathrm{CO}$, $\mathrm{NO}_{2}$, and $\mathrm{NH}_{3}$ molecules on graphene-like BC3: a search for highly sensitive molecular sensor," Applied Surface Science, vol. 427, pp. 326-333, 2018.

[2] W. G. Kreyling, M. Semmler-Behnke, and Q. Chaudhry, "A complementary definition of nanomaterial," Nano Today, vol. 5, no. 3, pp. 165-168, 2010.

[3] L.-M. Peng, Z. Zhang, and S. Wang, "Carbon nanotube electronics: recent advances," Materials Today, vol. 17, no. 9, pp. 433-442, 2014.

[4] A. F. Azevedo, M. R. Baldan, and N. G. Ferreira, "Nanodiamond films for applications in electrochemical systems," International Journal of Electrochemistry, vol. 2012, Article ID 508453, 16 pages, 2012.

[5] N. Nunn, M. Torelli, G. McGuire, and O. Shenderova, "Nanodiamond: a high impact nanomaterial," Current Opinion in Solid State and Materials Science, vol. 21, no. 1, pp. 1-9, 2017.

[6] A. M. Schrand, H. Huang, C. Carlson et al., "Are diamond nanoparticles cytotoxic?," Journal of Physical Chemistry B, vol. 111, no. 1, pp. 2-7, 2007.

[7] L.-W. Tsai, Y.-C. Lin, E. Perevedentseva, A. Lugovtsov, A. Priezzhev, and C.-L. Cheng, "Nanodiamonds for medical applications: interaction with blood in vitro and in vivo," International Journal of Molecular Sciences, vol. 17, no. 7, p. 1111, 2016.

[8] S. Osswald, G. Yushin, V. Mochalin, S. O. Kucheyev, and Y. Gogotsi, "Control of $\mathrm{sp}^{2} / \mathrm{sp}^{3}$ Carbon ratio and surface chemistry of nanodiamond powders by selective oxidation in air," Journal of the American Chemical Society, vol. 128, no. 35, pp. 11635-11642, 2006.

[9] T. Zheng, F. Perona Martínez, I. M. Storm et al., "Recombinant protein polymers for colloidal stabilization and improvement of cellular uptake of diamond nanosensors," Analytical Chemistry, vol. 89, no. 23, pp. 1281212820, 2017.

[10] V. N. Mochalin, O. Shenderova, D. Ho, and Y. Gogotsi, "The properties and applications of nanodiamonds," Nature Nanotechnology, vol. 7, no. 1, pp. 11-23, 2011.
[11] H. W. Kroto, J. R. Heath, S. C. O’Brien, R. F. Curl, and R. E. Smalley, "C60: buckminsterfullerene," Nature, vol. 318, no. 6042, pp. 162-163, 1985.

[12] P. A. Troshin and R. N. Lyubovskaya, "Organic chemistry of fullerenes: the major reactions, types of fullerene derivatives and prospects for practical use," Russian Chemical Reviews, vol. 77, no. 4, pp. 323-369, 2008.

[13] D. S. Klaus, Handbook of Nanophysics: Clusters and Fullerenes, CRC Press, Boca Raton, FL, USA, 2017.

[14] C. N. R. Rao, R. Seshadri, A. Govindaraj, and R. Sen, "Fullerenes, nanotubes, onions and related carbon structures," Materials Science and Engineering: R: Reports, vol. 15, no. 6, pp. 209-262, 1995.

[15] F. A. Zaghmarzi, M. Zahedi, A. Mola et al., "Fullerene-C60 and crown ether doped on C60 sensors for high sensitive detection of alkali and alkaline earth cations," Physica E: Low-dimensional Systems and Nanostructures, vol. 87, pp. 51-58, 2017.

[16] A. Hirsch, "The era of carbon allotropes," Nature Materials, vol. 9, no. 11, pp. 868-871, 2010.

[17] S. Iijima and T. Ichihashi, "Single-shell carbon nanotubes of 1-nm diameter," Nature, vol. 363, no. 6430, pp. 603-605, 1993.

[18] S. Iijima, "Helical microtubules of graphitic carbon," Nature, vol. 354, no. 6348, pp. 56-58, 1991.

[19] M. Monthioux and V. L. Kuznetsov, "Who should be given the credit for the discovery of carbon nanotubes?," Carbon, vol. 44, no. 9, pp. 1621-1623, 2006.

[20] K. S. Novoselov, "Electric field effect in atomically thin carbon films," Science, vol. 306, no. 5696, pp. 666-669, 2004.

[21] K. S. Novoselov, A. K. Geim, S. V. Morozov et al., "Twodimensional gas of massless Dirac fermions in graphene," Nature, vol. 438, no. 7065, pp. 197-200, 2005.

[22] P. Chen, T.-Y. Xiao, Y.-H. Qian, S.-S. Li, and S.-H. Yu, “A nitrogen-doped graphene/carbon nanotube nanocomposite with synergistically enhanced electrochemical activity," Advanced Materials, vol. 25, no. 23, pp. 3192-3196, 2013.

[23] E. Yilmaz, H. İ. Ulusoy, Ö. Demir, and M. Soylak, "A new magnetic nanodiamond/graphene oxide hybrid $\left(\mathrm{Fe}_{3} \mathrm{O}_{4} @\right.$ ND@GO) material for pre-concentration and sensitive determination of sildenafil in alleged herbal aphrodisiacs by HPLC-DAD system," Journal of Chromatography B, vol. 1084, pp. 113-121, 2018.

[24] P. Bindra and A. Hazra, "Capacitive gas and vapor sensors using nanomaterials," Journal of Materials Science: Materials in Electronics, vol. 29, no. 8, pp. 6129-6148, 2018.

[25] A. Ermakova, G. Pramanik, J.-M. Cai et al., "Detection of a few metallo-protein molecules using color centers in nanodiamonds," Nano Letters, vol. 13, no. 7, pp. 3305-3309, 2013.

[26] R. Schirhagl, K. Chang, M. Loretz, and C. L. Degen, "Nitrogen-vacancy centers in diamond: nanoscale sensors for physics and biology," Annual Review of Physical Chemistry, vol. 65, no. 1, pp. 83-105, 2014.

[27] G. Balasubramanian, P. Neumann, D. Twitchen et al., "Ultralong spin coherence time in isotopically engineered diamond," Nature Materials, vol. 8, no. 5, pp. 383-387, 2009.

[28] S. R. Hemelaar, A. Nagl, F. Bigot et al., "The interaction of fluorescent nanodiamond probes with cellular media," Microchimica Acta, vol. 184, no. 4, pp. 1001-1009, 2017.

[29] S. Y. Ong, M. Chipaux, A. Nagl, and R. Schirhagl, "Shape and crystallographic orientation of nanodiamonds for quantum sensing," Physical Chemistry Chemical Physics, vol. 19, no. 17, pp. 10748-10752, 2017. 
[30] S. Sutradhar and A. Patnaik, "A new fullerene-C60nanogold composite for non-enzymatic glucose sensing," Sensors and Actuators B: Chemical, vol. 241, pp. 681-689, 2017.

[31] P. Aruna and C. M. Joseph, "Spectral sensitivity of fullerene doped P3HT thin films for color sensing applications," Materials Today: Proceedings, vol. 5, no. 1, pp. 2412-2418, 2018.

[32] S. Sutradhar, G. V. Jacob, and A. Patnaik, "Structure and dynamics of a dl-homocysteine functionalized fullereneC60-gold nanocomposite: a femtomolar l-histidine sensor," Journal of Materials Chemistry B, vol. 5, no. 29, pp. 5835-5844, 2017.

[33] H. O. Pierson, "15-the fullerene molecules," in Pierson Graphite, Diamonds and Fullerenes HOBT-H of $C$, pp. 356-373, William Andrew Publishing, Oxford, UK, 1993.

[34] S. J. Tans, A. R. M. Verschueren, and C. Dekker, "Roomtemperature transistor based on a single carbon nanotube," Nature, vol. 393, no. 6680, pp. 49-52, 1998.

[35] Semiconductor Industry Association, Beyond CMOS, International Technology Roadmap for Semiconductors, vol. 20, pp. 1-93, 2015.

[36] S. Mohammad Ali Zanjani, M. Dousti, and M. Dolatshahi, "High-precision, resistor less gas pressure sensor and instrumentation amplifier in CNT technology," $A E U$ International Journal of Electronics and Communications, vol. 93, pp. 325-336, 2018.

[37] X. Chen, H. Pu, Z. Fu et al., "Real-time and selective detection of nitrates in water using graphene-based field-effect transistor sensors," Environmental Science: Nano, vol. 5, no. 8, pp. 1990-1999, 2018.

[38] S. Liu, T. Wu, F. Li, Q. Zhang, X. Dong, and L. Niu, "Disposable graphene sensor with an internal reference electrode for stripping analysis of heavy metals," Analytical Methods, vol. 10, no. 17, pp. 1986-1992, 2018.

[39] N. Lezi, "Fabrication of a "Green" and low-cost screenprinted graphene sensor and its application to the determination of caffeine by adsorptive stripping voltammetry," International Journal of Electrochemical Science, vol. 12, pp. 6054-6067, 2017.

[40] X. Leng, D. Luo, Z. Xu, and F. Wang, "Modified graphene oxide/nafion composite humidity sensor and its linear response to the relative humidity," Sensors and Actuators B: Chemical, vol. 257, pp. 372-381, 2018.

[41] L. Guo and T. Li, "Sub-ppb and ultra selective nitrogen dioxide sensor based on sulfur doped graphene," Sensors and Actuators B: Chemical, vol. 255, pp. 2258-2263, 2018.

[42] M. Kodu, A. Berholts, T. Kahro et al., "Graphene functionalised by laser-ablated $\mathrm{V}_{2} \mathrm{O}_{5}$ for a highly sensitive $\mathrm{NH}_{3}$ sensor," Beilstein Journal of Nanotechnology, vol. 8, pp. 571-578, 2017.

[43] O. Ovsianytskyi, Y.-S. Nam, O. Tsymbalenko, P.-T. Lan, M.-W. Moon, and K.-B. Lee, "Highly sensitive chemiresistive $\mathrm{H}_{2} \mathrm{~S}$ gas sensor based on graphene decorated with $\mathrm{Ag}$ nanoparticles and charged impurities," Sensors and Actuators B: Chemical, vol. 257, pp. 278-285, 2018.

[44] I. V. Zaporotskova, N. P. Boroznina, Y. N. Parkhomenko, and L. V. Kozhitov, "Carbon nanotubes: sensor properties. A review," Modern Electronic Materials, vol. 2, no. 4, pp. 95105, 2016.

[45] J. Wu, S. Feng, X. Wei et al., "Facile synthesis of 3D Graphene flowers for ultrasensitive and highly reversible gas sensing,"
Advanced Functional Materials, vol. 26, no. 41, pp. 74627469, 2016.

[46] United States Environmental Protection Agency, Primary National Ambient Air Quality Standards (NAAQS) for Nitrogen Dioxide, United States Environmental Protection Agency, Washington, DC, USA, 2018, https://www.epa.gov/ no2-pollution/primary-national.

[47] Y. Seekaew, D. Phokharatkul, A. Wisitsoraat, and C. Wongchoosuk, "Highly sensitive and selective roomtemperature $\mathrm{NO}_{2}$ gas sensor based on bilayer transferred chemical vapor deposited graphene," Applied Surface Science, vol. 404, pp. 357-363, 2017.

[48] F. Ricciardella, S. Vollebregt, T. Polichetti et al., "Effects of graphene defects on gas sensing properties towards $\mathrm{NO}_{2}$ detection," Nanoscale, vol. 9, no. 18, pp. 6085-6093, 2017.

[49] J. Wu, K. Tao, J. Miao, and L. K. Norford, "Threedimensional hierarchical and superhydrophobic graphene gas sensor with good immunity to humidity," in Proceedings of 2018 IEEE Micro Electro Mechanical Systems (MEMS), pp. 901-904, Belfast, UK, January 2018.

[50] J. Kang, F. Huo, P. Ning, X. Meng, J. Chao, and C. Yin, “Two red-emission single and double 'arms' fluorescent materials stemed from 'one-pot' reaction for hydrogen sulfide vivo imaging," Sensors and Actuators B: Chemical, vol. 250, pp. 342-350, 2017.

[51] F. Huo, Y. Zhang, P. Ning, X. Meng, and C. Yin, “A novel isophorone-based red-emitting fluorescent probe for selective detection of sulfide anions in water for in vivo imaging," Journal of Materials Chemistry B, vol. 5, no. 15, pp. 27982803, 2017.

[52] S. Keshtkar, A. Rashidi, M. Kooti et al., "A novel highly sensitive and selective $\mathrm{H}_{2} \mathrm{~S}$ gas sensor at low temperatures based on $\mathrm{SnO}_{2}$ quantum dots-C60 nanohybrid: experimental and theory study," Talanta, vol. 188, pp. 531-539, 2018.

[53] I. H. R. Abbasi, F. Abbasi, M. E. Abd El-Hack et al., "Critical analysis of excessive utilization of crude protein in ruminants ration: impact on environmental ecosystem and opportunities of supplementation of limiting amino acids-a review," Environmental Science and Pollution Research, vol. 25, no. 1, pp. 181-190, 2018.

[54] X. Chen, Z. Huang, J. Li, C. Wu, Z. Wang, and Y. Cui, "Methane gas sensing behavior of lithium ion doped carbon nanotubes sensor," Vacuum, vol. 154, pp. 120-128, 2018.

[55] B. M. Jaidev, M. Baro, and S. Ramaprabhu, "Room temperature hydrogen gas sensing properties of mono dispersed platinum nanoparticles on graphene-like carbon-wrapped carbon nanotubes," International Journal of Hydrogen Energy, vol. 43, no. 33, pp. 16421-16429, 2018.

[56] N. A. Algadri, Z. Hassan, K. Ibrahim, and A. M. AL-Diabat, "A high-sensitivity hydrogen gas sensor based on carbon nanotubes fabricated on glass substrate," Journal of Electronic Materials, vol. 47, no. 11, pp. 6671-6680, 2018.

[57] Y. Wang and J. T. W. Yeow, "A review of carbon nanotubesbased gas sensors," Journal of Sensors, vol. 2009, Article ID 493904, 24 pages, 2009.

[58] D. Smazna, J. Rodrigues, S. Shree et al., "Buckminsterfullerene hybridized zinc oxide tetrapods: defects and charge transfer induced optical and electrical response," Nanoscale, vol. 10, no. 21, pp. 10050-10062, 2018.

[59] W. Zhao, C. Yang, D. Zou, Z. Sun, and G. Ji, "Possibility of gas sensor based on C20 molecular devices," Physics Letters A, vol. 381, no. 21, pp. 1825-1830, 2017.

[60] R. Rahimi, S. Kamalinahad, and M. Solimannejad, "Adsorption of rare gases on the C20 nanocage: a theoretical 
investigation," Materials Research Express, vol. 5, no. 3, article 35006, 2018.

[61] H. Song, Y. Zhang, and J. Cao, "Sensing mechanism of an ionization gas temperature sensor based on a carbon nanotube film," RSC Advances, vol. 7, no. 84, pp. 5326553269, 2017.

[62] H. Song, K. Li, and Q. Li, "A tripolar-electrode ionization gas sensor using a carbon nanotube cathode for NO detection," Journal of Micromechanics and Microengineering, vol. 28, no. 6, article 65010, 2018.

[63] L. T. Duy, D.-J. Kim, T. Q. Trung et al., "High performance three-dimensional chemical sensor platform using reduced graphene oxide formed on high aspect-ratio micro-pillars," Advanced Functional Materials, vol. 25, no. 6, pp. 883-890, 2015.

[64] F. Schedin, A. K. Geim, S. V. Morozov et al., "Detection of individual gas molecules adsorbed on graphene," Nature Materials, vol. 6, no. 9, pp. 652-655, 2007.

[65] J. Eriksson, D. Puglisi, Y. H. Kang, R. Yakimova, and A. Lloyd Spetz, "Adjusting the electronic properties and gas reactivity of epitaxial graphene by thin surface metallization," Physica B: Condensed Matter, vol. 439, pp. 105-108, 2014.

[66] F. Yavari, E. Castillo, H. Gullapalli, P. M. Ajayan, and N. Koratkar, "High sensitivity detection of $\mathrm{NO}_{2}$ and $\mathrm{NH}_{3}$ in air using chemical vapor deposition grown graphene," Applied Physics Letters, vol. 100, no. 20, article 203120, 2012.

[67] G. Lee, G. Yang, A. Cho, J. W. Han, and J. Kim, "Defectengineered graphene chemical sensors with ultrahigh sensitivity," Physical Chemistry Chemical Physics, vol. 18, no. 21, pp. 14198-14204, 2016.

[68] R. Lv, G. Chen, Q. Li et al., "Ultrasensitive gas detection of large-area boron-doped graphene," Proceedings of the $\mathrm{Na}$ tional Academy of Sciences, vol. 112, no. 47, pp. 14527-14532, 2015.

[69] Z. Song, Z. Wei, B. Wang et al., "Sensitive room-temperature $\mathrm{H}_{2} \mathrm{~S}$ gas sensors employing $\mathrm{SnO}_{2}$ quantum wire/reduced graphene oxide nanocomposites," Chemistry of Materials, vol. 28, no. 4, pp. 1205-1212, 2016.

[70] S.-J. Choi, B.-H. Jang, S.-J. Lee, B. K. Min, A. Rothschild, and I.-D. Kim, "Selective detection of acetone and hydrogen sulfide for the diagnosis of diabetes and halitosis using $\mathrm{SnO}_{2}$ nanofibers functionalized with reduced graphene oxide nanosheets," ACS Applied Materials \& Interfaces, vol. 6, no. 4, pp. 2588-2597, 2014.

[71] J. Tian, F. Pan, R. Xue et al., "A highly sensitive room temperature $\mathrm{H}_{2} \mathrm{~S}$ gas sensor based on $\mathrm{SnO}_{2}$ multi-tube arrays bio-templated from insect bristles," Dalton Transactions, vol. 44, no. 17, pp. 7911-7916, 2015.

[72] M. K. Kumar and S. Ramaprabhu, "Nanostructured Pt functionlized multiwalled carbon nanotube based hydrogen sensor," Journal of Physical Chemistry B, vol. 110, no. 23, pp. 11291-11298, 2006.

[73] A. Kaniyoor, R. Imran Jafri, T. Arockiadoss, and S. Ramaprabhu, "Nanostructured Pt decorated graphene and multi walled carbon nanotube based room temperature hydrogen gas sensor," Nanoscale, vol. 1, no. 3, p. 382, 2009.

[74] D. Jung, M. Han, and G. S. Lee, "Fast-response room temperature hydrogen gas sensors using platinum-coated spin-capable carbon nanotubes," ACS Applied Materials \& Interfaces, vol. 7, no. 5, pp. 3050-3057, 2015.

[75] M. Krishnakumar and S. Ramaprabhu, "Palladium dispersed multiwalled carbon nanotube based hydrogen sensor for fuel cell applications," International Journal of Hydrogen Energy, vol. 32, no. 13, pp. 2518-2526, 2007.

[76] L. K. Randeniya, P. J. Martin, and A. Bendavid, "Detection of hydrogen using multi-walled carbon-nanotube yarns coated with nanocrystalline $\mathrm{Pd}$ and $\mathrm{Pd} / \mathrm{Pt}$ layered structures," Carbon, vol. 50, no. 5, pp. 1786-1792, 2012.

[77] U. Yaqoob, A. S. M. I. Uddin, and G.-S. Chung, "Foldable hydrogen sensor using Pd nanocubes dispersed into multiwall carbon nanotubes-reduced graphene oxide network assembled on nylon filter membrane," Sensors and Actuators B: Chemical, vol. 229, pp. 355-361, 2016.

[78] D. Ding, Z. Chen, S. Rajaputra, and V. Singh, "Hydrogen sensors based on aligned carbon nanotubes in an anodic aluminum oxide template with palladium as a top electrode," Sensors and Actuators B: Chemical, vol. 124, no. 1, pp. 12-17, 2007.

[79] J. Kong, M. G. Chapline, and H. Dai, "Functionalized carbon nanotubes for molecular hydrogen sensors," Advanced Materials, vol. 13, no. 18, pp. 1384-1386, 2001.

[80] K. Guo and A. H. Jayatissa, "Hydrogen sensing properties of multi-walled carbon nanotubes," Materials Science and Engineering: C, vol. 28, no. 8, pp. 1556-1559, 2008.

[81] S. Majumdar, P. Nag, and P. S. Devi, "Enhanced performance of $\mathrm{CNT} / \mathrm{SnO}_{2}$ thick film gas sensors towards hydrogen," Materials Chemistry and Physics, vol. 147, no. 1-2, pp. 79-85, 2014.

[82] L. M. Holland and G. J. Doole, "Implications of fairness for the design of nitrate leaching policy for heterogeneous New Zealand dairy farms," Agricultural Water Management, vol. 132, pp. 79-88, 2014.

[83] R. M. Monaghan, M. J. Hedley, H. J. Di, R. W. McDowell, K. C. Cameron, and S. F. Ledgard, "Nutrient management in New Zealand pastures-recent developments and future issues," New Zealand Journal of Agricultural Research, vol. 50, no. 2, pp. 181-201, 2007.

[84] M. E. E. Alahi, A. Nag, S. C. Mukhopadhyay, and L. Burkitt, "A temperature-compensated graphene sensor for nitrate monitoring in real-time application," Sensors and Actuators A: Physical, vol. 269, pp. 79-90, 2018.

[85] Z.-N. Wei, X.-X. Yang, Z.-H. Mo, and F. Leng, "Photocatalytic sensor of organics in water with signal of plasmonic swing," Sensors and Actuators B: Chemical, vol. 255, pp. 3458-3463, 2018.

[86] Z. Heidari and M. Masrournia, "A novel modified carbon paste electrode for the determination of chromium(III) in water," Journal of Analytical Chemistry, vol. 73, no. 8, pp. 824-831, 2018.

[87] L. Jiang, I. Santiago, and J. Foord, "Nanocarbon and nanodiamond for high performance phenolics sensing," Communications Chemistry, vol. 1, no. 1, p. 43, 2018.

[88] T.-W. Chen, "Sensitive and low-potential electrochemical detection of hydroquinone using a nanodiamond modified glassy carbon electrode," International Journal of Electrochemical Science, vol. 12, pp. 8021-8032, 2017.

[89] M. Li, H. Gou, I. Al-Ogaidi, and N. Wu, "Nanostructured sensors for detection of heavy metals: a review," ACS Sustainable Chemistry \& Engineering, vol. 1, no. 7, pp. 713-723, 2013.

[90] S. Zhang, H. Zhu, P. Ma, F. Duan, W. Dong, and M. Du, “A self-supported electrochemical sensor for simultaneous sensitive detection of trace heavy metal ions based on PtAu alloy/carbon nanofibers," Analytical Methods, vol. 9, no. 48, pp. 6801-6807, 2017.

[91] X. Niu, Y. Zhong, R. Chen, F. Wang, Y. Liu, and D. Luo, “A "turn-on" fluorescence sensor for $\mathrm{Pb}^{2+}$ detection based on 
graphene quantum dots and gold nanoparticles," Sensors and Actuators B: Chemical, vol. 255, pp. 1577-1581, 2018.

[92] X. Xuan and J. Y. Park, "A miniaturized and flexible cadmium and lead ion detection sensor based on micropatterned reduced graphene oxide/carbon nanotube/ bismuth composite electrodes," Sensors and Actuators B: Chemical, vol. 255, pp. 1220-1227, 2018.

[93] F. Menacer, Z. Dibi, and A. Kadri, "Modeling a new acetone sensor based on carbon nanotubes using finite elements and neural network," European Physical Journal Plus, vol. 133, no. 6 , p. $238,2018$.

[94] L. O. Porciúncula, C. Sallaberry, S. Mioranzza, P. H. S. Botton, and D. B. Rosemberg, "The Janus face of caffeine," Neurochemistry International, vol. 63, no. 6, pp. 594-609, 2013.

[95] L. A. B. Persad, "Energy drinks and the neurophysiological impact of caffeine," Front Neurosci, vol. 5, 2011.

[96] M. Ghaedi, A. Shokrollahi, A. R. Salimibeni, S. Noshadi, and S. Joybar, "Preparation of a new chromium(III) selective electrode based on 1-[(2-hydroxy ethyl) amino]-4-methyl9H-thioxanthen-9-one as a neutral carrier," Journal of Hazardous Materials, vol. 178, no. 1-3, pp. 157-163, 2010.

[97] R. K. Sharma and A. Goel, "Development of a Cr(III)-specific potentiometric sensor using Aurin tricarboxylic acid modified silica," Analytica Chimica Acta, vol. 534, no. 1, pp. 137-142, 2005.

[98] L. Cao, H. Sun, J. Li, and L. Lu, "An enhanced electrochemical platform based on graphene-polyoxometalate nanomaterials for sensitive determination of diphenolic compounds," Analytical Methods, vol. 3, no. 7, p. 1587, 2011.

[99] L. Wang, P.-f. Huang, H.-j. Wang, J.-y. Bai, L.-y. Zhang, and Y.-q. Zhao, "Covalent modification of glassy carbon electrode with aspartic acid for simultaneous determination of hydroquinone and catechol," Annali di Chimica, vol. 97, no. 5-6, pp. 395-404, 2007.

[100] G. Hwang, W. Han, J. Park, and S. Kang, "Determination of trace metals by anodic stripping voltammetry using a bismuth-modified carbon nanotube electrode," Talanta, vol. 76, no. 2, pp. 301-308, 2008.

[101] M. F. Philips, A. I. Gopalan, and K.-P. Lee, "Development of a novel cyano group containing electrochemically deposited polymer film for ultrasensitive simultaneous detection of trace level cadmium and lead," Journal of Hazardous Materials, vol. 237-238, pp. 46-54, 2012.

[102] X. Li, G. Wang, X. Ding, Y. Chen, Y. Gou, and Y. Lu, “A "turn-on" fluorescent sensor for detection of $\mathrm{Pb}^{2+}$ based on graphene oxide and G-quadruplex DNA," Physical Chemistry Chemical Physics, vol. 15, no. 31, article 12800, 2013.

[103] L. Jiang, Y. Ding, F. Jiang, L. Li, and F. Mo, "Electrodeposited nitrogen-doped graphene/carbon nanotubes nanocomposite as enhancer for simultaneous and sensitive voltammetric determination of caffeine and vanillin," Analytica Chimica Acta, vol. 833, pp. 22-28, 2014.

[104] M. A. Raj and S. A. John, "Simultaneous determination of uric acid, xanthine, hypoxanthine and caffeine in human blood serum and urine samples using electrochemically reduced graphene oxide modified electrode," Analytica Chimica Acta, vol. 771, pp. 14-20, 2013.

[105] A. Wilkes and D. Williams, "Measurement of humidity," Anaesthesia \& Intensive Care Medicine, vol. 19, no. 4, pp. 198-201, 2018.

[106] H. Hamouche, S. Makhlouf, A. Chaouchi, and M. Laghrouche, "Humidity sensor based on keratin bio polymer film," Sensors and Actuators A: Physical, vol. 282, pp. 132-141, 2018.

[107] X. Li, X. Chen, X. Chen, X. Ding, and X. Zhao, "Highsensitive humidity sensor based on graphene oxide with evenly dispersed multiwalled carbon nanotubes," Materials Chemistry and Physics, vol. 207, pp. 135-140, 2018.

[108] M. Rodahl, F. Höök, and B. Kasemo, "QCM operation in liquids: an explanation of measured variations in frequency andqfactor with liquid conductivity," Analytical Chemistry, vol. 68, no. 13, pp. 2219-2227, 1996.

[109] R. Lv, J. Peng, S. Chen et al., "A highly linear humidity sensor based on quartz crystal microbalance coated with urea formaldehyde resin/nano silica composite films," Sensors and Actuators B: Chemical, vol. 250, pp. 721-725, 2017.

[110] X. Ding, X. Chen, X. Chen, X. Zhao, and N. Li, “A QCM humidity sensor based on fullerene/graphene oxide nanocomposites with high quality factor," Sensors and Actuators B: Chemical, vol. 266, pp. 534-542, 2018.

[111] X. Yu, X. Chen, H. Li, and X. Ding, "A high-stability QCM Humidity sensor coated with nanodiamond/multiwalled carbon nanotubes nanocomposite," IEEE Transactions on Nanotechnology, vol. 17, no. 3, pp. 506-512, 2018.

[112] S. C. Hens, G. Cunningham, G. McGuire, and O. Shenderova, "Nanodiamond-assisted dispersion of carbon nanotubes and hybrid nanocarbon-based composites," Nanoscience and Nanotechnology Letters, vol. 3, no. 1, pp. 75-82, 2011.

[113] D. Saha and S. Das, "Development of fullerene modified metal oxide thick films for moisture sensing application," Materials Today: Proceedings, vol. 5, no. 3, pp. 9817-9825, 2018.

[114] H. P. Hong, K. H. Jung, J. H. Kim et al., "Percolated pore networks of oxygen plasma-activated multi-walled carbon nanotubes for fast response, high sensitivity capacitive humidity sensors," Nanotechnology, vol. 24, no. 8, article 085501, 2013.

[115] J. J. Steele, G. A. Fitzpatrick, and M. J. Brett, "Capacitive humidity sensors with high sensitivity and subsecond response times," IEEE Sensors Journal, vol. 7, no. 6, pp. 955-956, 2007.

[116] Y. Yao, X. Chen, X. Li, X. Chen, and N. Li, "Investigation of the stability of QCM humidity sensor using graphene oxide as sensing films," Sensors and Actuators B: Chemical, vol. 191, pp. 779-783, 2014.

[117] X. Li, X. Chen, Y. Yao, N. Li, X. Chen, and X. Bi, "Multiwalled carbon nanotubes/graphene oxide composites for humidity sensing," IEEE Sensors Journal, vol. 13, no. 12, pp. 4749-4756, 2013.

[118] R. E. Newnham, Properties of Materials: Anisotropy, Symmetry, Structure, Oxford University Press, New York, NY, USA, 2005.

[119] J. Cao, Q. Wang, and H. Dai, "Electromechanical properties of metallic, quasimetallic, and semiconducting carbon nanotubes under stretching," Physical Review Letters, vol. 90, no. 15 , article 157601, 2003.

[120] M. Amjadi, A. Pichitpajongkit, S. Lee, S. Ryu, and I. Park, "Highly stretchable and sensitive strain sensor based on silver nanowire-elastomer nanocomposite," ACS Nano, vol. 8, no. 5, pp. 5154-5163, 2014.

[121] S. Yu, X. Wang, H. Xiang, L. Zhu, M. Tebyetekerwa, and M. Zhu, "Superior piezoresistive strain sensing behaviors of carbon nanotubes in one-dimensional polymer fiber structure," Carbon, vol. 140, pp. 1-9, 2018. 
[122] X. Ma, Y. Dong, and R. Li, "Monitoring technology in composites using carbon nanotube yarns based on piezoresistivity," Materials Letters, vol. 188, pp. 45-47, 2017.

[123] M. F. Arif, S. Kumar, T. K. Gupta, and K. M. Varadarajan, "Strong linear-piezoresistive-response of carbon nanostructures reinforced hyperelastic polymer nanocomposites," Composites Part A: Applied Science and Manufacturing, vol. 113, pp. 141-149, 2018.

[124] P. Zhao, S. Wang, A. Kadlec, Z. Li, and X. Wang, "Properties of cement-sand-based piezoelectric composites with carbon nanotubes modification," Ceramics International, vol. 42, no. 13, pp. 15030-15034, 2016.

[125] D. Cho, J. Park, J. Kim et al., "Three-dimensional continuous conductive nanostructure for highly sensitive and stretchable strain sensor," ACS Applied Materials \& Interfaces, vol. 9, no. 20, pp. 17369-17378, 2017.

[126] Y. Zheng, Y. Li, K. Dai et al., "A highly stretchable and stable strain sensor based on hybrid carbon nanofillers/ polydimethylsiloxane conductive composites for large human motions monitoring," Composites Science and Technology, vol. 156, pp. 276-286, 2018.

[127] X. Li, W. Huang, G. Yao et al., "Highly sensitive flexible tactile sensors based on microstructured multiwall carbon nanotube arrays," Scripta Materialia, vol. 129, pp. 61-64, 2017.

[128] Y. Gao, G. Yu, J. Tan, and F. Xuan, "Sandpaper-molded wearable pressure sensor for electronic skins," Sensors and Actuators A: Physical, vol. 280, pp. 205-209, 2018.

[129] T. Giffney, E. Bejanin, A. S. Kurian, J. Travas-Sejdic, and K. Aw, "Highly stretchable printed strain sensors using multi-walled carbon nanotube/silicone rubber composites," Sensors and Actuators A: Physical, vol. 259, pp. 44-49, 2017.

[130] T. H. da Costa and J.-W. Choi, "A flexible two dimensional force sensor using PDMS nanocomposite,” Microelectronic Engineering, vol. 174, pp. 64-69, 2017.

[131] H. J. Kim and Y. J. Kim, "High performance flexible piezoelectric pressure sensor based on CNTs-doped 0-3 ceramic-epoxy nanocomposites," Materials \& Design, vol. 151, pp. 133-140, 2018.

[132] X. Dong, Y. Wei, S. Chen, Y. Lin, L. Liu, and J. Li, "A linear and large-range pressure sensor based on a graphene/silver nanowires nanobiocomposites network and a hierarchical structural sponge," Composites Science and Technology, vol. 155, pp. 108-116, 2018.

[133] K. Bhatt, C. Rani, M. Vaid et al., "A comparative study of graphene and graphite-based field effect transistor on flexible substrate," Pramana, vol. 90, no. 6, p. 75, 2018.

[134] B. B. Prasad, R. Singh, and A. Kumar, "Synthesis of fullerene (C60-monoadduct)-based water-compatible imprinted micelles for electrochemical determination of chlorambucil," Biosensors and Bioelectronics, vol. 94, pp. 115-123, 2017.

[135] J. S. Farias, H. Zanin, A. S. Caldas, C. C. dos Santos, F. S. Damos, and R. de Cássia Silva Luz, "Functionalized multiwalled carbon nanotube electrochemical sensor for determination of anticancer drug flutamide," Journal of Electronic Materials, vol. 46, no. 10, pp. 5619-5628, 2017.

[136] N. B. Simioni, T. A. Silva, G. G. Oliveira, and O. FatibelloFilho, "A nanodiamond-based electrochemical sensor for the determination of pyrazinamide antibiotic," Sensors and Actuators B: Chemical, vol. 250, pp. 315-323, 2017.

[137] R. Ahmadi, M. R. Jalali Sarvestani, and B. Sadeghi, "Computational study of the fullerene effects on the properties of 16 different drugs: a review," International Journal of Nano Dimension, vol. 9, no. 4, pp. 325-335, 2018.
[138] C. Parlak and Ö. Alver, "A density functional theory investigation on amantadine drug interaction with pristine and B, Al, Si, Ga, Ge doped C60 fullerenes," Chemical Physics Letters, vol. 678, pp. 85-90, 2017.

[139] S. Bashiri, E. Vessally, A. Bekhradnia, A. Hosseinian, and L. Edjlali, "Utility of extrinsic [60] fullerenes as work function type sensors for amphetamine drug detection: DFT studies," Vacuum, vol. 136, pp. 156-162, 2017.

[140] M. Moradi, M. Nouraliei, and R. Moradi, "Theoretical study on the phenylpropanolamine drug interaction with the pristine, Si and Al doped [60] fullerenes," Physica E: Lowdimensional Systems and Nanostructures, vol. 87, pp. 186191, 2017.

[141] M. Rahimi-Nasrabadi, A. Khoshroo, and M. MazloumArdakani, "Electrochemical determination of diazepam in real samples based on fullerene-functionalized carbon nanotubes/ionic liquid nanocomposite," Sensors and Actuators B: Chemical, vol. 240, pp. 125-131, 2017.

[142] F. Ahmadi, J. B. Raoof, R. Ojani, M. Baghayeri, M. M. Lakouraj, and H. Tashakkorian, "Synthesis of Ag nanoparticles for the electrochemical detection of anticancer drug flutamide," Chinese Journal of Catalysis, vol. 36, no. 3, pp. 439-445, 2015.

[143] P. K. Brahman, R. A. Dar, S. Tiwari, and K. S. Pitre, "Voltammetric determination of anticancer drug flutamide in surfactant media at polymer film modified carbon paste electrode," Colloids and Surfaces A: Physicochemical and Engineering Aspects, vol. 396, pp. 8-15, 2012.

[144] S. Mani, S. Cheemalapati, S. Chen, and B. Ming Devadas, "Anti-tuberculosis drug pyrazinamide determination at multiwalled carbon nanotubes/graphene oxide hybrid composite fabricated electrode," International Journal of Electrochemical Science, vol. 10, pp. 7049-7062, 2015.

[145] M. E. Lozano-Chaves, J. M. Palacios-Santander, L. M. Cubillana-Aguilera, I. Naranjo-Rodríguez, and J. L. Hidalgo-Hidalgo-de-Cisneros, "Modified carbon-paste electrodes as sensors for the determination of 1,4-benzodiazepines: application to the determination of diazepam and oxazepam in biological fluids," Sensors and Actuators B: Chemical, vol. 115, no. 2, pp. 575-583, 2006.

[146] M. A. Zare, M. S. Tehrani, S. W. Husain, and P. A. Azar, "Multiwall carbon nanotube-ionic liquid modified paste electrode as an efficient sensor for the determination of diazepam and oxazepam in real samples," Electroanalysis, vol. 26, no. 12, pp. 2599-2606, 2014.

[147] W. Wei, J. Nong, Y. Zhu et al., "Graphene/Au-enhanced plastic clad silica fiber optic surface plasmon resonance sensor," Plasmonics, vol. 13, no. 2, pp. 483-491, 2018.

[148] H. Jeong, D. M. Nguyen, M. S. Lee, H. G. Kim, S. C. Ko, and L. K. Kwac, "N-doped graphene-carbon nanotube hybrid networks attaching with gold nanoparticles for glucose nonenzymatic sensor," Materials Science and Engineering: C, vol. 90, pp. 38-45, 2018.

[149] Y. Liu, A. Kannegulla, B. Wu, and L.-J. Cheng, "Quantum dot fullerene-based molecular beacon nanosensors for rapid, highly sensitive nucleic acid detection," ACS Applied Materials \& Interfaces, vol. 10, no. 22, pp. 18524-18531, 2018.

[150] M.-J. Li, Y.-N. Zheng, W.-B. Liang, R. Yuan, and Y.-Q. Chai, "Using p-type $\mathrm{PbS}$ quantum dots to quench photocurrent of fullerene-Au NP@MoS${ }_{2}$ composite structure for ultrasensitive photoelectrochemical detection of ATP," ACS Applied Materials \& Interfaces, vol. 9, no. 48, pp. 42111-42120, 2017.

[151] Y. Hao, P. Yan, X. Zhang et al., "Ultrasensitive amperometric determination of PSA based on a signal amplification 
strategy using nanoflowers composed of single-strand DNA modified fullerene and Methylene Blue, and an improved surface-initiated enzymatic polymerization," Microchimica Acta, vol. 184, no. 11, pp. 4341-4349, 2017.

[152] C. Zhang, J. He, Y. Zhang et al., "Cerium dioxide-doped carboxyl fullerene as novel nanoprobe and catalyst in electrochemical biosensor for amperometric detection of the CYP2C19*2 allele in human serum," Biosensors and Bioelectronics, vol. 102, pp. 94-100, 2018.

[153] P. Chen, T. Wang, X. Zheng, D. Tian, F. Xia, and C. Zhou, "An ultrasensitive electrochemical immunosensor based on C60-modified polyamidoamine dendrimers and Au NPs for CO-catalytic silver deposition," New Journal of Chemistry, vol. 42, no. 6, pp. 4653-4660, 2018.

[154] Z. O. Uygun, Ç. Şahin, M. Yılmaz, Y. Akçay, A. Akdemir, and F. Sağın, "Fullerene-PAMAM(G5) composite modified impedimetric biosensor to detect Fetuin-A in real blood samples," Analytical Biochemistry, vol. 542, pp. 11-15, 2018.

[155] S. Nag, M. Castro, V. Choudhary, and J.-F. Feller, "Sulfonated poly(ether ether ketone) [SPEEK] nanocomposites based on hybrid nanocarbons for the detection and discrimination of some lung cancer VOC biomarkers," Journal of Materials Chemistry B, vol. 5, no. 2, pp. 348-359, 2017.

[156] Ö. Alver, C. Parlak, P. Ramasami, and M. Şenyel, "Interaction between doped C60 fullerenes and piperazine2,3,5,6-tetraone: DFT simulation," Main Group Metal Chemistry, vol. 41, no. 3-4, pp. 63-66, 2018.

[157] Ö. Alver, C. Parlak, P. Ramasami, and M. Şenyel, "Density functional theory study on the adsorption of valproic acid to doped fullerenes," Main Group Metal Chemistry, vol. 41, no. 3-4, pp. 67-71, 2018.

[158] J. Ma, C. Yang, S. Zhu, J. Song, and Y. Fu, “A new nanomatrix based on functionalized fullerene and porous bimetallic nanoparticles for electrochemical chiral sensing," New Journal of Chemistry, vol. 42, no. 12, pp. 98019807, 2018.

[159] F. Valentini, E. Ciambella, F. Cataldo, A. Calcaterra, L. Menegatti, and M. Talamo, "Fullerene black modified screen printed electrodes for the quantification of acetaminophen and guanine," Electroanalysis, vol. 29, no. 12, pp. 2863-2872, 2017.

[160] T. L. Tran, T. T. Nguyen, T. T. Huyen Tran, V. T. Chu, Q. Thinh Tran, and A. Tuan Mai, "Detection of influenza A virus using carbon nanotubes field effect transistor based DNA sensor," Physica E: Low-dimensional Systems and Nanostructures, vol. 93, pp. 83-86, 2017.

[161] A. Dudina, F. Seichepine, Y. Chen, A. Stettler, A. Hierlemann, and U. Frey, "Monolithic CMOS sensor platform featuring an array of 9'216 carbon-nanotube-sensor elements and low-noise, wide-bandwidth and widedynamic-range readout circuitry," Sensors and Actuators B: Chemical, vol. 279, pp. 255-266, 2018.

[162] S. Hemelaar, B. Saspaanithy, S. L'Hommelet, F. Perona Martinez, K. van der Laan, and R. Schirhagl, "The response of HeLa cells to fluorescent NanoDiamond uptake," Sensors, vol. 18 , no. 2, p. 355, 2018.

[163] D. A. Simpson, E. Morrisroe, J. M. McCoey et al., "Nonneurotoxic nanodiamond probes for intraneuronal temperature mapping," ACS Nano, vol. 11, no. 12, pp. 1207712086, 2017.

[164] V. Kumar, R. Mahajan, I. Kaur, and K.-H. Kim, "Simple and mediator-free urea sensing based on engineered nanodiamonds with polyaniline nanofibers synthesized in situ,"
ACS Applied Materials \& Interfaces, vol. 9, no. 20, pp. 16813-16823, 2017.

[165] M. S. Purdey, P. K. Capon, B. J. Pullen et al., “An organic fluorophore-nanodiamond hybrid sensor for photostable imaging and orthogonal, on-demand biosensing," Scientific Reports, vol. 7, no. 1, p. 15967, 2017.

[166] Q. Cao, Y. Teng, X. Yang, J. Wang, and E. Wang, "A labelfree fluorescent molecular beacon based on DNA-Ag nanoclusters for the construction of versatile Biosensors," Biosensors and Bioelectronics, vol. 74, pp. 318-321, 2015.

[167] P. R. Solanki, A. Kaushik, A. A. Ansari, G. Sumana, and B. D. Malhotra, "Zinc oxide-chitosan nanobiocomposite for urea sensor," Applied Physics Letters, vol. 93, no. 16, article 163903, 2008.

[168] R. K. Srivastava, S. Srivastava, T. N. Narayanan et al., "Functionalized multilayered graphene platform for urea sensor," ACS Nano, vol. 6, no. 1, pp. 168-175, 2012.

[169] T. Zhang, G.-Q. Liu, W.-H. Leong et al., "Hybrid nanodiamond quantum sensors enabled by volume phase transitions of hydrogels," Nature Communications, vol. 9, no. 1, p. 3188, 2018.

[170] R. G. Ryan, A. Stacey, K. M. O’Donnell et al., "Impact of Surface functionalization on the quantum coherence of nitrogen-vacancy centers in nanodiamonds," ACS Applied Materials \& Interfaces, vol. 10, no. 15, pp. 13143-13149, 2018.

[171] M. Bricha and K. El Mabrouk, "Effect of surfactants on the degree of dispersion of MWNTs in ethanol solvent," Colloids and Surfaces A: Physicochemical and Engineering Aspects, vol. 561, pp. 57-69, 2019.

[172] S. Claveau, J.-R. Bertrand, and F. Treussart, "Fluorescent nanodiamond applications for cellular process sensing and cell tracking," Micromachines, vol. 9, no. 5, p. 247, 2018.

[173] T. Rosskopf, A. Dussaux, K. Ohashi et al., "Investigation of surface magnetic noise by shallow spins in diamond," Physical Review Letters, vol. 112, no. 14, article 147602, 2014.

[174] M. S. Dresselhaus, G. Dresselhaus, and P. C. Eklund, Chapter 3-Structure of Fullerenes, Academic Press, San Diego, CA, USA, 1996.

[175] V. Augusto, C. Baleizão, M. N. Berberan-Santos, and J. P. S. Farinha, "Oxygen-proof fluorescence temperature sensing with pristine C70encapsulated in polymernanoparticles," Journal of Materials Chemistry, vol. 20, no. 6, pp. 1192-1197, 2010.

[176] J. R. Baena, M. Gallego, and M. Valcárcel, "Fullerenes in the analytical sciences," TrAC Trends in Analytical Chemistry, vol. 21, no. 3, pp. 187-198, 2002.

[177] W. Shao, P. Arghya, M. Yiyong, L. Rodes, and S. Prakash, "Carbon nanotubes for use in medicine: potentials and limitations," in Syntheses and Applications of Carbon Nanotubes and Their Composites, S. Suzuki, Ed., p. 29, IntechOpen, London, UK, 2013.

[178] L. Camilli and M. Passacantando, "Advances on sensors based on carbon nanotubes," Chemosensors, vol. 6, no. 4, p. 62, 2018.

[179] R. Rafiee and R. Pourazizi, "Evaluating the influence of defects on the young's modulus of carbon nanotubes using stochastic modeling," Materials Research, vol. 17, no. 3, pp. 758-766, 2014.

[180] A. Nag, A. Mitra, and S. C. Mukhopadhyay, "Graphene and its sensor-based applications: a review," Sensors and Actuators A: Physical, vol. 270, pp. 177-194, 2018.

[181] D. R. Dreyer, S. Park, C. W. Bielawski, and R. S. Ruoff, "The chemistry of graphene oxide," Chemical Society Reviews, vol. 39, no. 1, pp. 228-240, 2010. 
[182] S.-M. Lee, J.-H. Kim, and J.-H. Ahn, "Graphene as a flexible electronic material: mechanical limitations by defect formation and efforts to overcome," Materials Today, vol. 18, no. 6, pp. 336-344, 2015.

[183] Y. Wu, Y.-m. Lin, A. A. Bol et al., "High-frequency, scaled graphene transistors on diamond-like carbon," Nature, vol. 472, no. 7341, pp. 74-78, 2011.

[184] D. A. C. Brownson and C. E. Banks, "CVD graphene electrochemistry: the role of graphitic islands," Physical Chemistry Chemical Physics, vol. 13, no. 35, pp. 15825-15828, 2011.

[185] S. Gupta Chatterjee, S. Chatterjee, A. K. Ray, and A. K. Chakraborty, "Graphene-metal oxide nanohybrids for toxic gas sensor: a review," Sensors and Actuators B: Chemical, vol. 221, pp. 1170-1181, 2015.

[186] M. Qiao, Q. Ran, and S. Wu, "Novel star-like surfactant as dispersant for multi-walled carbon nanotubes in aqueous suspensions at high concentration," Applied Surface Science, vol. 433, pp. 975-982, 2018. 


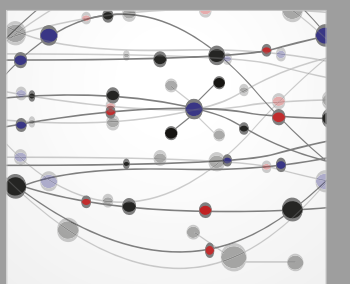

The Scientific World Journal
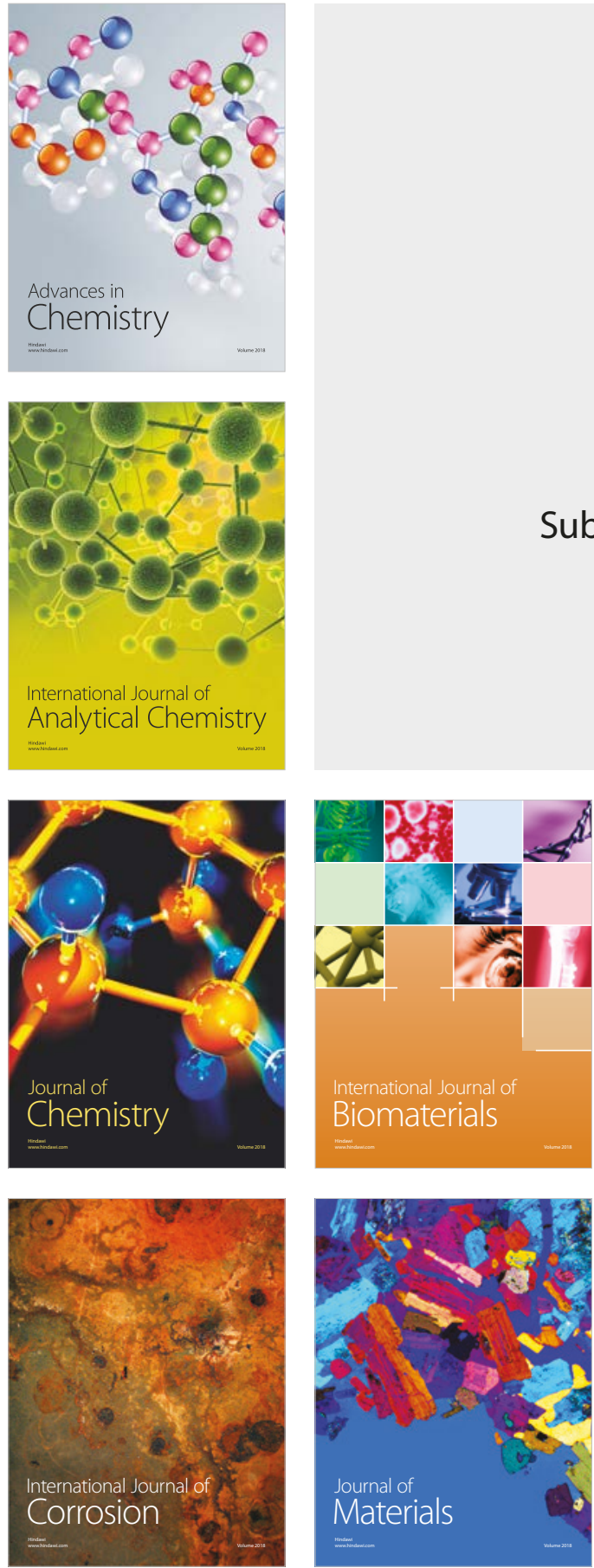

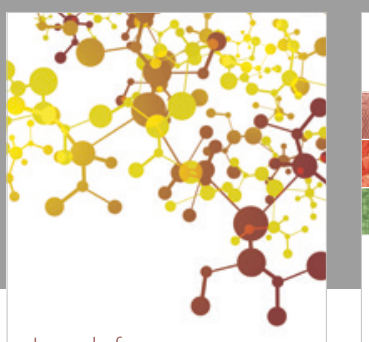

Journal of

Applied Chemistry
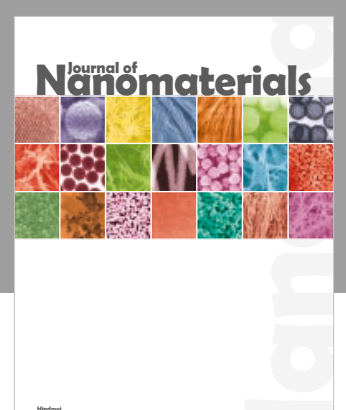

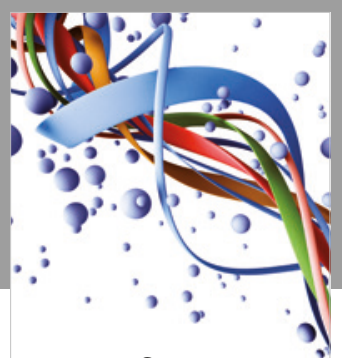

Scientifica

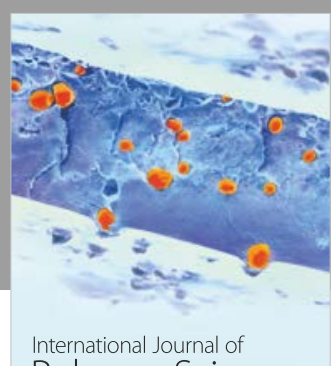

Polymer Science

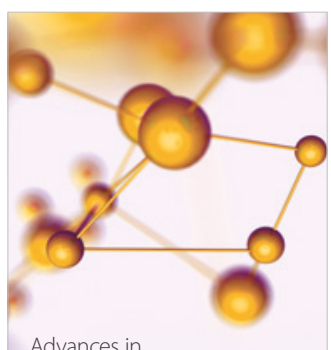

Physical Chemistry
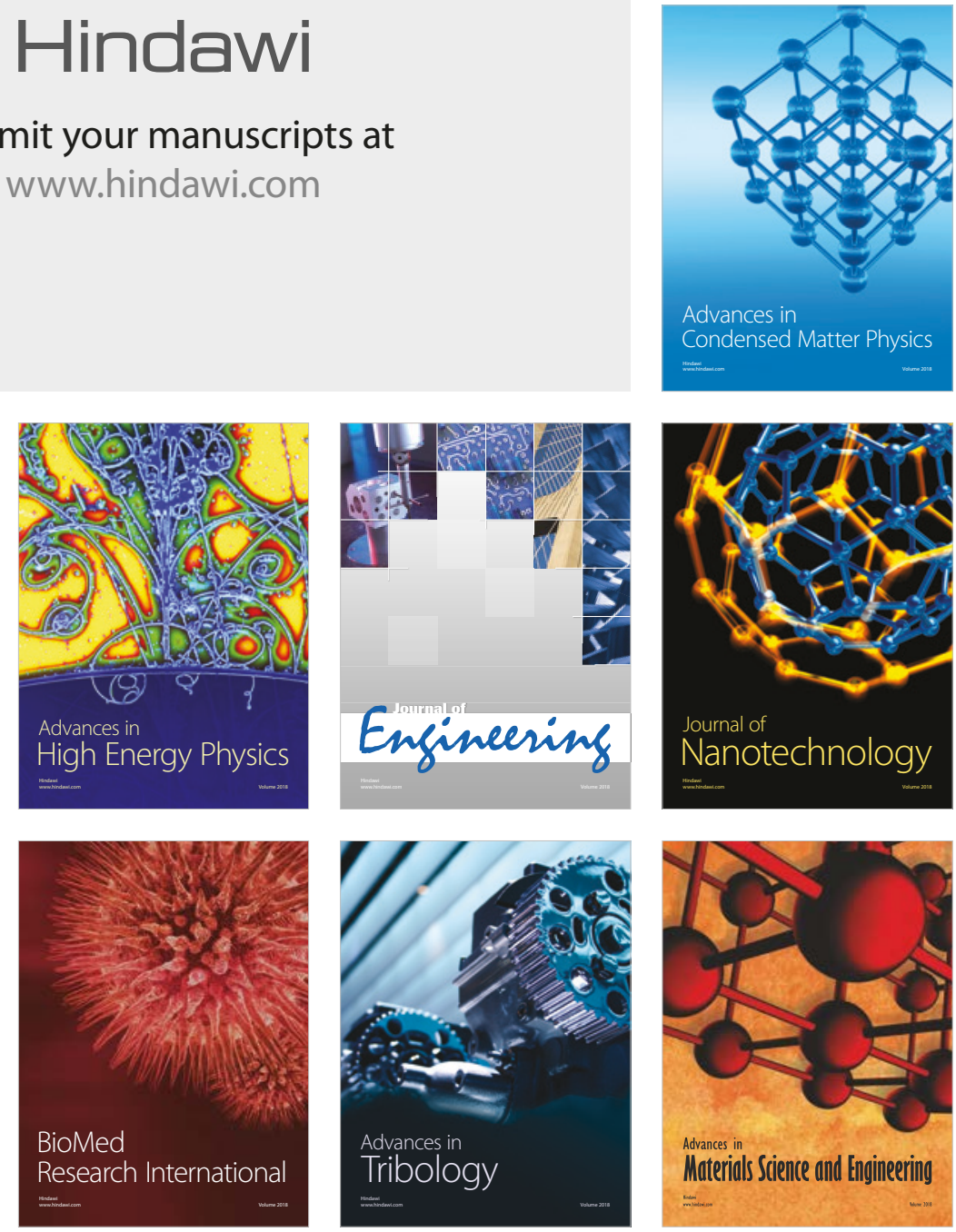